\title{
Elastic Asymmetry of PLA Material in FDM-Printed Parts: Considerations Concerning Experimental Characterisation for Use in Numerical Simulations
}

\author{
Ma-Magdalena Pastor-Artigues ${ }^{1, *(\mathbb{D}}$, Francesc Roure-Fernández ${ }^{1}$, Xavier Ayneto-Gubert ${ }^{1}(\mathbb{D}$, \\ Jordi Bonada-Bo $^{1}$, Elsa Pérez-Guindal ${ }^{2}$ and Irene Buj-Corral ${ }^{3}$ iD \\ 1 Department of Strength of Materials and Structural Engineering (RMEE), Barcelona School of Industrial \\ Engineering (ETSEIB), Universitat Politècnica de Catalunya-Barcelona Tech (UPC), 08028 Barcelona, Spain; \\ francesc.roure@upc.edu (F.R.-F.); javier.ayneto@upc.edu (X.A.-G.); jordi.bonada@upc.edu (J.B.-B.) \\ 2 Department of Strength of Materials and Structural Engineering (RMEE), Vilanova i la Geltrú School of \\ Engineering (EPSEVG), Universitat Politècnica de Catalunya-Barcelona Tech (UPC), \\ 08800 Vilanova i la Geltrú, Spain; elsa.perez@upc.edu \\ 3 Department of Mechanical Engineering (EM), Barcelona School of Industrial Engineering (ETSEIB), \\ Universitat Politècnica de Catalunya-Barcelona Tech (UPC), 08028 Barcelona, Spain; irene.buj@upc.edu \\ * Correspondence: m.magdalena.pastor@upc.edu; Tel.: +34-93-401-6532
}

Received: 31 October 2019; Accepted: 15 December 2019; Published: 18 December 2019

\begin{abstract}
The objective of this research is to characterise the material poly lactic acid (PLA), printed by fused deposition modelling (FDM) technology, under three loading conditions-tension, compression and bending-in order to get data that will allow to simulate structural components. In the absence of specific standards for materials manufactured in FDM technology, characterisation is carried out based on ASTM International standards D638, D695 and D790, respectively. Samples manufactured with the same printing parameters have been built and tested; and the tensile, compressive and flexural properties have been determined. The influences of the cross-sectional shape and the specimen length on the strength and elastic modulus of compression are addressed. By analysing the mechanical properties obtained in this way, the conclusion is that they are different, are not coherent with each other, and do not reflect the bimodular nature (different behaviour of material in tension and compression) of this material. A finite element (FE) model is used to verify these differences, including geometric non-linearity, to realistically reproduce conditions during physical tests. The main conclusion is that the test methods currently used do not guarantee a coherent set of mechanical properties useful for numerical simulation, which highlights the need to define new characterisation methods better adapted to the behaviour of FDM-printed PLA.
\end{abstract}

Keywords: FDM; PLA; mechanical properties; bimodulus materials; standards; finite element analysis (FEA)

\section{Introduction}

Additive manufacturing (AM) technologies allow for converting virtual models into physical models in a quick and easy way by means of tool-free processes. Different polymeric materials are being produced for 3D Printing (3DP) with a wider range of properties. 3DP has many applications in sectors such as automotive, electronics or medical [1]. Aliphatic polyesters, in particular poly lactic acid (PLA), are suitable materials for in vivo applications because of their biocompatibility, biodegradability, good mechanical strength and processability. PLA is the most researched and used aliphatic biodegradable polyester. It is a leading biomaterial for numerous applications in both medicine and industry, and the ability to adapt its properties for specific applications makes the market capacity of PLA products 
very broad, which has catalysed an extensive and growing amount of research aimed at the use of this material in innovative forms and applications [2-7].

If PLA-printed parts are to be usable as real industrial or biomechanical components, their structural and mechanical reliability has to be proved by means of strength and stiffness verifications. These will be done by classical strength of materials calculations or by finite element (FE) simulations. In either case, it is essential to have a coherent set of mechanical properties of the material under the different service conditions (tension, compression, bending, torsion, etc.). Flexural strength and tensile strength are two of the most commonly used values for comparing plastic materials. Compressive strength gives a good indication of short-term load capacities. Rigidity is expressed by the modulus of elasticity in tension and flexion. Reference data on the mechanical properties of PLA are available in the literature [2,8-14], with the tensile test being the most common of the tests performed to characterise the mechanical behaviour of PLA [15-21].

However, information of the bulk material behaviour is not always useful for carrying out numerical simulations to check the proper in-service behaviour of a fused deposition modelling (FDM)-printed component. To simulate the behaviour of a FDM-printed component, it is previously necessary to characterise the material in the same way that it is in the component. Many works start from the existing standards for polymeric materials to characterise also their FDM-printed versions. The ASTM standards D638 (tensile properties), D695 (compressive properties) and D790 (flexural properties) are widely used for this purpose.

The objective of this work was to obtain the mechanical properties of parts printed on PLA for use in numerical simulations, and to contrast the procedures for such purposes based on the use of ASTM standards. The results obtained considering an isotropic behaviour were compared for the different types of loads in the standards (tension, compression and bending). Nevertheless, when considering the bimodular behaviour of the material [22-25], inconsistencies were observed between the results obtained in the different tests. Differences in compression behaviour were also observed depending on the shape and proportions of the samples.

It is concluded that the currently accepted approach, based on characterisation according to the above standards (or the equivalent ISO standards), is not suitable for this purpose. It is necessary to define new characterisation methods that take into account of the bimodularity of the material and ensure a consistent set of mechanical characteristics for numerical simulation. This will be the next step of this research.

\section{Test Methods}

The PLA samples were 3D-printed with FDM technology, in a BCN3D Sigma v17 machine (BCN3D Technologies, Barcelona, Spain). It is an FDM desktop 3D printer with an independent dual extruder.

Specifications and properties of the PLA filament, provided by the manufacturer of the machine, are shown in Table 1.

Table 1. Filament specifications and properties

\begin{tabular}{cc}
\hline Specification/Parameter & Value \\
\hline Diameter $(\mathrm{mm})$ & 2.85 \\
Specific gravity (ISO 1183) $\left(\mathrm{g} / \mathrm{cm}^{3}\right)$ & 1.24 \\
Tensile strength at yield (ISO 527) $(\mathrm{MPa})$ & 70 \\
Strain at yield (ISO 527) $(\%)$ & 5 \\
Strain at break (ISO 527) $(\%)$ & 20 \\
Tensile modulus (ISO 527) $(\mathrm{MPa})$ & 3120 \\
Melting temperature (ISO 11357) $\left({ }^{\circ} \mathrm{C}\right)$ & $115 \pm 35$ \\
Glass transition temperature (ISO 11357) $\left({ }^{\circ} \mathrm{C}\right)$ & 57 \\
Molecular weight $(\mathrm{g} / \mathrm{mol})$ & $1.598 \times$ \\
& $10^{5}$ \\
\hline
\end{tabular}


The slicing software was Cura 0.1.5. All the specimens were manufactured with constant printing parameters, which are provided in Table 2.

Table 2. Printing parameters.

\begin{tabular}{cc}
\hline Parameter & Value \\
\hline Infill ratio $(\%)$ & 90 \\
Nozzle diameter $(\mathrm{mm})$ & 0.4 \\
Printing temperature $\left({ }^{\circ} \mathrm{C}\right)$ & 205 \\
Printing speed $(\mathrm{mm} / \mathrm{s})$ & 50 \\
Printing pattern & Rectangular \\
Raster angle $\left({ }^{\circ}\right)$ & 45 \\
Layer height $(\mathrm{mm})$ & 0.1 \\
\hline
\end{tabular}

Anisotropy as well as the influence of different printing parameters, like infill percentage or printing speed, were beyond the scope of this study.

ASTM (American Society for Testing and Materials) and ISO (International Organization for Standardization) mechanical testing standards are widely used to determine mechanical properties of plastics. These test procedures assume the material is continuous and homogeneous, although not necessarily isotropic. They do not include particular considerations for additive manufacturing [26,27]. Forster [28] reviews existing procedures for testing polymers and analyses their feasibility for additive manufacturing processes. It should be mentioned; however, that there are technical committees working on developing new standards for additive manufacturing (ISO/TC261, ASTM F42).

ASTM D638-02a Standard Test Method for Tensile Properties of Plastics [29], ASTM D695-02a Standard Test Method for Compressive Properties of Rigid Plastics [30] and ASTM D790-02 Flexural Properties of Unreinforced and Reinforced Plastics and Electrical Insulating Materials [31] were followed in the tests carried out.

As regards the shape and dimensions of the specimens tested, the recommendations of the standards were followed. For the tensile and bending tests, the options were quite clear; however, in the case of the compression test, two cross-section shapes were possible, and the specimen length depended on the mechanical property to be obtained.

\subsection{Specimens}

The shape and dimensions of the specimens were defined in accordance with the standards (Figures 1-3) as above mentioned, and six samples of each series were manufactured: One set of specimens for tensile tests, another set for bending tests, and four sets for compression tests, where two different cross-section shapes and two different specimen lengths were possible.
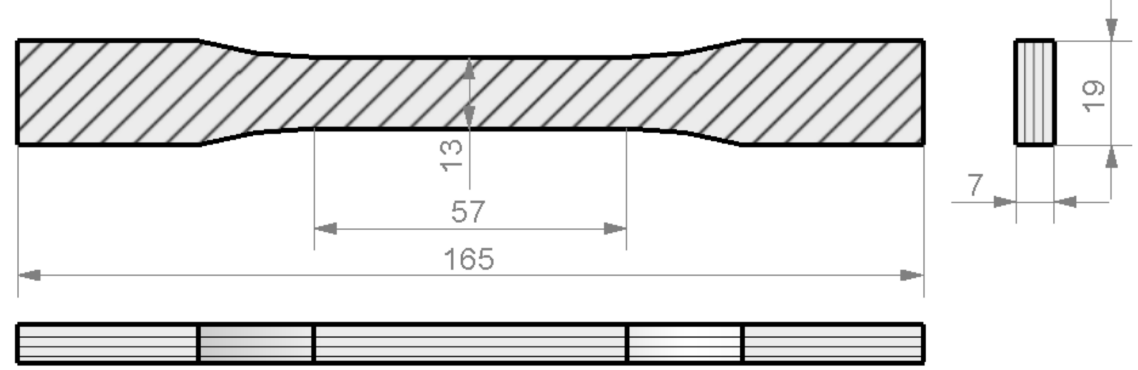

Figure 1. Drawing of the tensile test specimen (dimensions in $\mathrm{mm}$ ). 

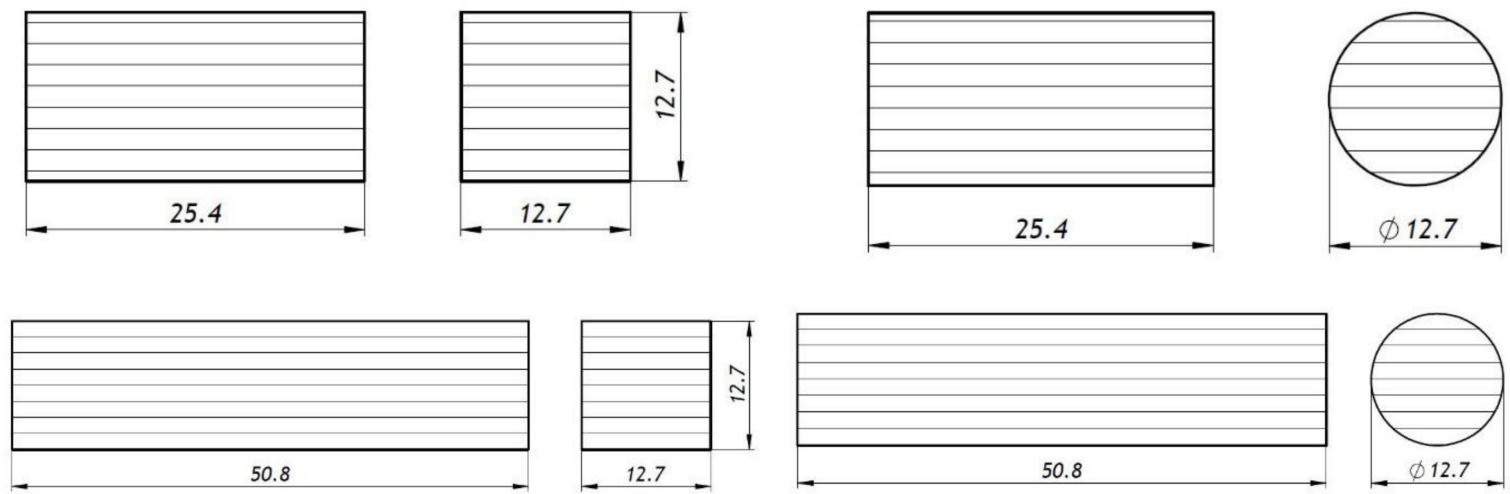

Figure 2. Drawing of the compression test specimens (dimensions in $\mathrm{mm}$ ).

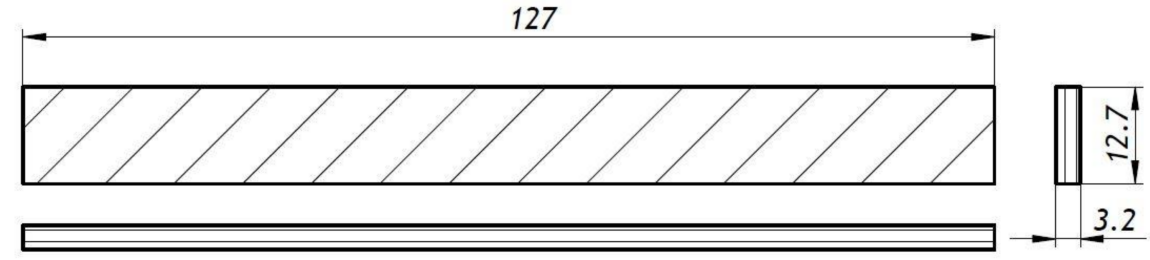

Figure 3. Drawing of the three-point bending test specimen (dimensions in $\mathrm{mm}$ ).

As mentioned above, the printing parameters were kept constant (Table 2). The layers were oriented in the direction of the stresses. Figure 4 shows the print raster and the direction of the layers.
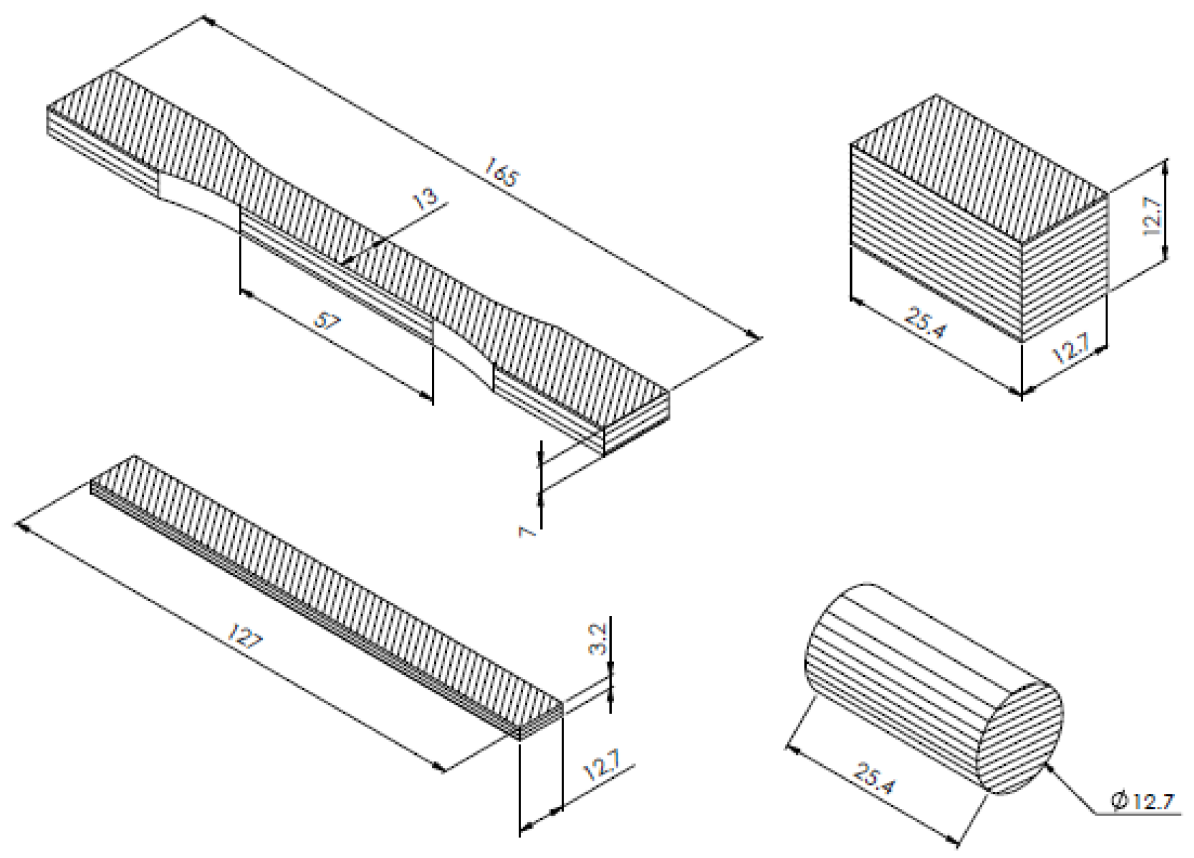

Figure 4. Structure of specimens with the raster and layers.

Figure 5 shows the 36 PLA 3D-printed samples grouped in six sets. 


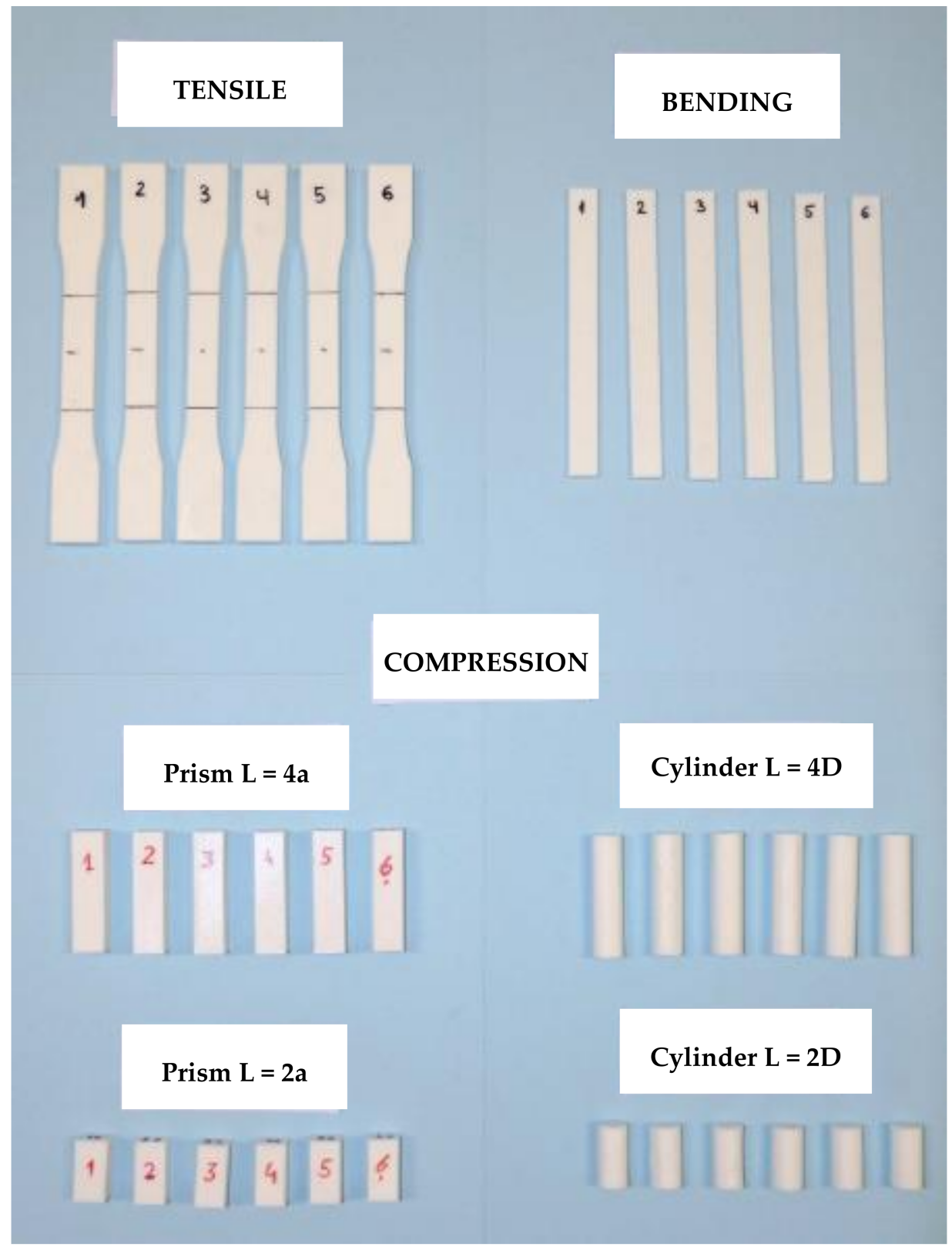

Figure 5. Poly Lactic Acid (PLA) samples for mechanical testing.

All test specimens were weighed on a KERN 400-55N precision scale (KERN \& SOHN GmbH, Balingen, Germany), and measures were taken by means of a calliper to obtain the actual dimensions of each one of them. Tensile, compression and three-point bending tests were performed. All of them were carried out by means of an INSTRON machine model 3366 (INSTRON ${ }^{\circledR}$, MA, USA) with the necessary equipment for each test.

\subsection{Experimental Tests}

\subsubsection{Tensile Test}

According to the ASTM D638 standard [29], the speed of testing was set at $5 \mathrm{~mm} / \mathrm{min}$ and the load-extension curve of the specimen was recorded. Longitudinal (INSTRON 2630-102) and transverse (INSTRON I3575-250M-ST) strain measuring devices (extensometers) were attached to the specimen in order to determine the Poisson's ratio (Figure 6) (INSTRON $\left.{ }^{\circledR}, \mathrm{MA}, \mathrm{USA}\right)$. 


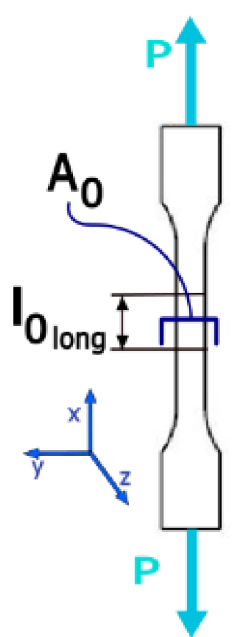

(a)

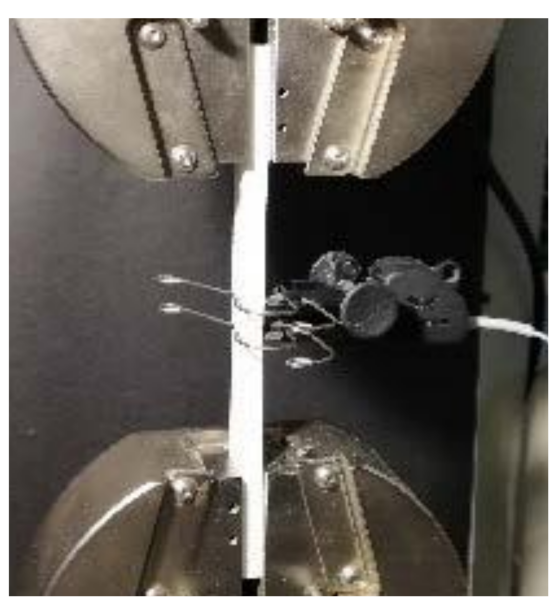

(b)

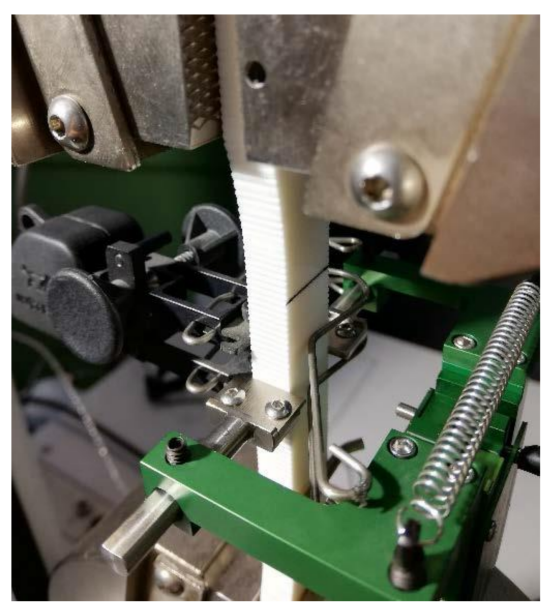

(c)

Figure 6. Tensile test assembly. Tensile test diagram (a); the longitudinal (b) and transverse (c) extensometers fitted on the specimen are shown.

From the data recorded during the test, the values of stress $(\sigma)$, strain $(\varepsilon)$ and modulus of elasticity (E) were calculated (Equation (1)).

$$
\left\{\sigma=\frac{P}{A_{0}} \quad \varepsilon=\frac{\Rightarrow l}{l_{0}} \quad E=\frac{\sigma}{\varepsilon},\right.
$$

where:

$P$ = tensile load;

$A_{0}=$ initial cross-sectional area;

$\Delta l=$ increment of distance between gauge marks;

$l_{0}=$ initial specimen gauge length .

\subsubsection{Compression Test}

In the case of the compression test, the ASTM D695 standard [30] specifies that the test specimen shall be in the form of a right cylinder or prism (square), whose length is twice its width or diameter. However, when the modulus of elasticity and offset yield-stress are desired, the test specimen shall be of such dimensions that the slenderness ratio $(\lambda)$ is in the range from 11 to 16:1. In this case, the preferred specimen sizes were 12.7 (a) by 12.7 (a) by $50.8 \mathrm{~mm}$ (L) (prism), or 12.7 in diameter (D) by $50.8 \mathrm{~mm}$ (L) (cylinder) (Figure 7). In literature consulted concerning this test, the length of the specimens was usually twice its principal width or diameter. Exceptionally [32-35] long-length specimens were tested.

$$
\lambda=\frac{L}{i}=\frac{L}{\sqrt{\frac{I}{A}}}=\left\{\begin{array}{c}
\frac{L}{\sqrt{\frac{\pi}{\frac{6}{4} D^{4}}}}=\frac{4 L}{D} \in[11,16] \Rightarrow L \in[2.75 D, 4 D] \text { for cylinder } \\
\frac{L}{\sqrt{\frac{\frac{1}{12} a^{4}}{a^{2}}}}=\frac{2 \sqrt{3} L}{a} \in[11,16] \Rightarrow L \in[3.2 a, 4.6 a] \text { for prism (square) }
\end{array},\right.
$$

where:

$i=$ least radius of gyration;

$I=$ moment of inertia;

$A=$ area of the cross-section. 


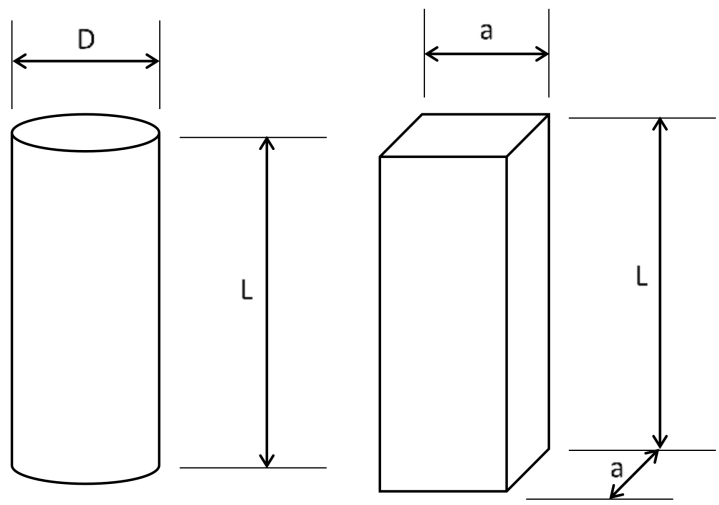

Figure 7. Dimensions of compression test specimens.

Limiting the slenderness ratio $(\lambda)$ to the range 11 to $16: 1$ avoids 1$)$ the influence of the end conditions on the results and 2) the buckling of the sample in the elastic range of the test.

Four series of specimens were built, called short specimens $(L=2 a, L=2 D)$ and long specimens $(\mathrm{L}=4 \mathrm{a}, \mathrm{L}=4 \mathrm{D}$ ), whose length values were in the range given by Equation (2).

The speed of testing was set at $1.3 \mathrm{~mm} / \mathrm{min}$ for short specimens $(\mathrm{L}=2 \mathrm{a}, \mathrm{L}=2 \mathrm{D})$ in accordance with paragraph 9 of the standard, and at $2.6 \mathrm{~mm} / \mathrm{min}$ for long specimens $(\mathrm{L}=4 \mathrm{a}, \mathrm{L}=4 \mathrm{D})$, thus preserving the constant strain rate in all tests.

The test setup is shown in Figure 8.

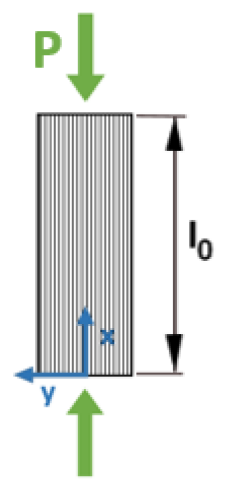

(a)

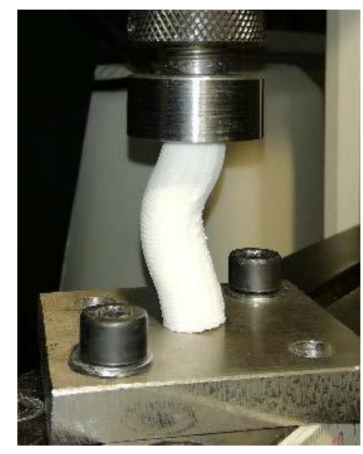

(b)

Figure 8. Compression test diagram (a); long specimen at the end of the test (b).

In a similar way to the tensile test, the values of stress $(\sigma)$, strain $(\varepsilon)$ and modulus of elasticity $(E)$ were calculated (Equation (1)).

\subsubsection{Three-Point Bending Test}

The three-point bending test was performed in accordance with ASTM D790 [31]. Figure 9 illustrates the test setup. The dimensions of the specimens can be seen in Figure 3.

The machine was set for the rate of crosshead motion $(R)$ calculated according to Equation (3) taken from the standard:

$$
R=\frac{Z L^{2}}{6 h}=\frac{0.01 \times 52^{2}}{6 \times 3.2} \approx 1.4 \mathrm{~mm} / \mathrm{min},
$$

where:

$$
L=\operatorname{support} \operatorname{span}(52 \mathrm{~mm}) \text {; }
$$


$h=$ depth of beam $(3.2 \mathrm{~mm})$;

$Z=$ rate of strain of the outer fibre $(\mathrm{mm} / \mathrm{mm} / \mathrm{min})$, where $Z$ shall be equal to 0.01 .

The test ended when the deformation reached $5 \%$, which was equivalent to a vertical displacement ( $\delta$ ) of $7 \mathrm{~mm}$ (Procedure A).

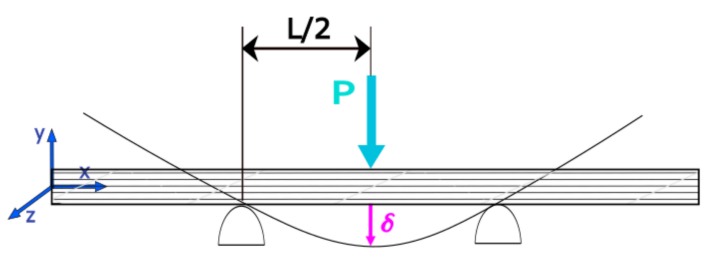

(a)

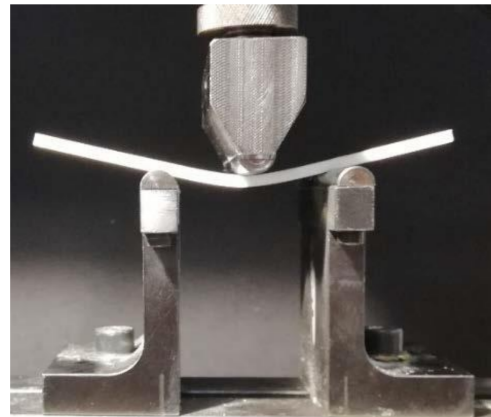

(b)

Figure 9. Bending test diagram (a); specimen under loading (b).

The flexural stress $\left(\sigma_{f}\right)$ and flexural strain $\left(\varepsilon_{f}\right)$ were calculated according to Equation (4). The flexural modulus of elasticity $\left(\mathrm{E}_{\mathrm{B}}\right)$ is calculated from Equation (5).

$$
\left\{\sigma_{f}=\frac{3 P L}{2 b h^{2}} \quad \varepsilon_{f}=\frac{6 \delta h}{L^{2}},\right.
$$

where:

$P=$ load at a given point on the load-deflection curve $(\mathrm{N})$;

$b=$ width of beam tested $(\mathrm{mm})$

\subsection{Numerical Test}

Finite Element (FE) analyses were carried out previously to reproduce mechanical testing on ABS 3D-printed parts [36,37]. When using experimental data in numerical models, it is important to ascertain under what conditions the mechanical properties were obtained [34].

This section presents a first approximation of a finite element model of the compression test. A three-dimensional model is shown that does not include the internal structure of the material. The software used was ANSYS ${ }^{\circledR}$ Academic Research Mechanical, Release 19.1 [38].

- $\quad$ The simplified hypotheses assumed in the model were:

- Nominal dimensions were used to define the geometry of the sample

- The behaviour of the material was assumed to be linear, elastic and isotropic

- Neither the porosity of the material nor the manufacturing process was simulated. Figure 10 shows an enlarged image of the surface of one of the specimens, where the porosity and internal structure of the material is seen.

- Only a quarter of the specimen was modelled due to the symmetry of the analysis (Figure 11).

The features of the analysis were:

- Finite element Solid 186-3D, 20-node-was used for prismatic and cylindrical specimens;

- Material data $(\mathrm{E}, v)$ found from experimental tests were introduced;

- The analysis was geometrically non-linear (GNA). Through an iterative process (Newton-Raphson), an equilibrium of forces was reached at each load step. The loading process was controlled by displacements. 


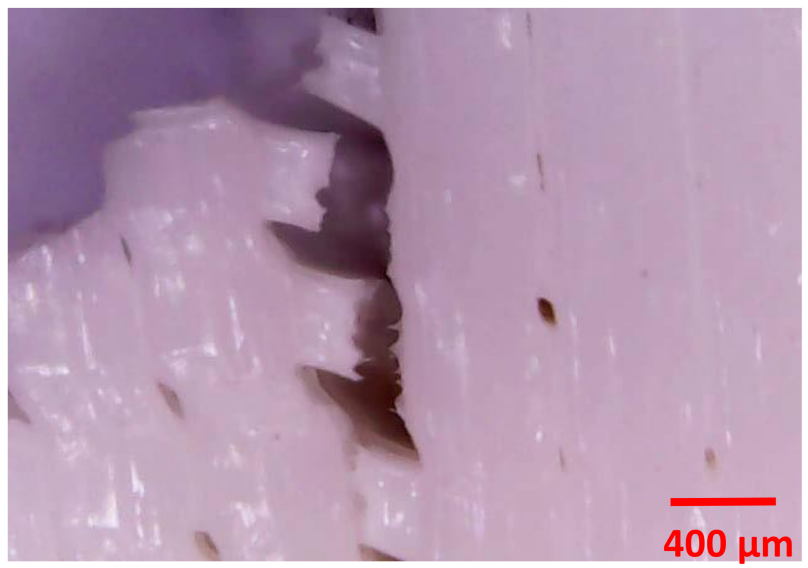

Figure 10. Enlargement of the surface area of a sample, where the porous nature of the material can be seen.

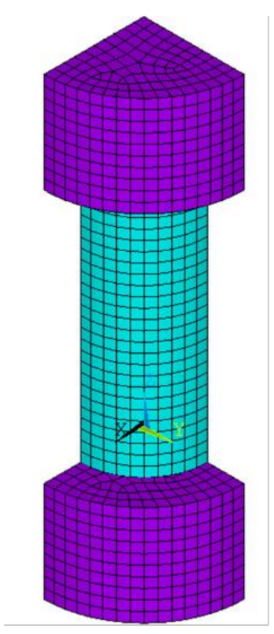

(a)

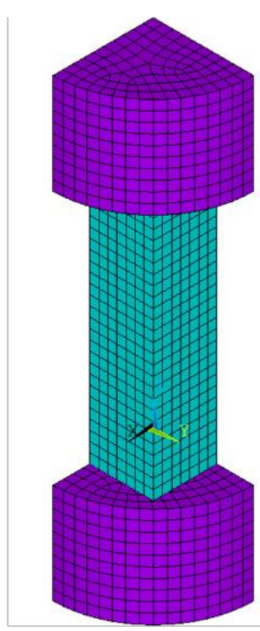

(b)

Figure 11. Finite element model for the cylindrical (a) and prismatic (b) short specimens. The purple elements correspond to the steel plates of the testing equipment.

The analysis reproduced the conditions of the compression test. The steel plates of the test setup were also simulated, and a contact between the specimen and the steel was introduced with a coefficient of friction of approximately 0.4 [39]. To define the boundary conditions, the bottom line of the bottom steel plate was fixed with zero displacement in all directions, and a negative vertical displacement was defined in the top steel plate. Symmetry boundary conditions were introduced at the two planes of symmetry.

\section{Results}

\subsection{Results of Experimental Tests}

\subsubsection{Tensile Test Results}

Figure 12 shows the stress-strain curves, overlapped for all specimens. Figure 13 illustrates the tensile failure of a sample after the test.

The modulus of elasticity $(E)$, strength $(\sigma)$, elongation $(\varepsilon)$ and Poisson's ratio $(v)$ were derived from the data recorded during the test and subsequent calculations following the recommendations of the standard (Equation (1)). 


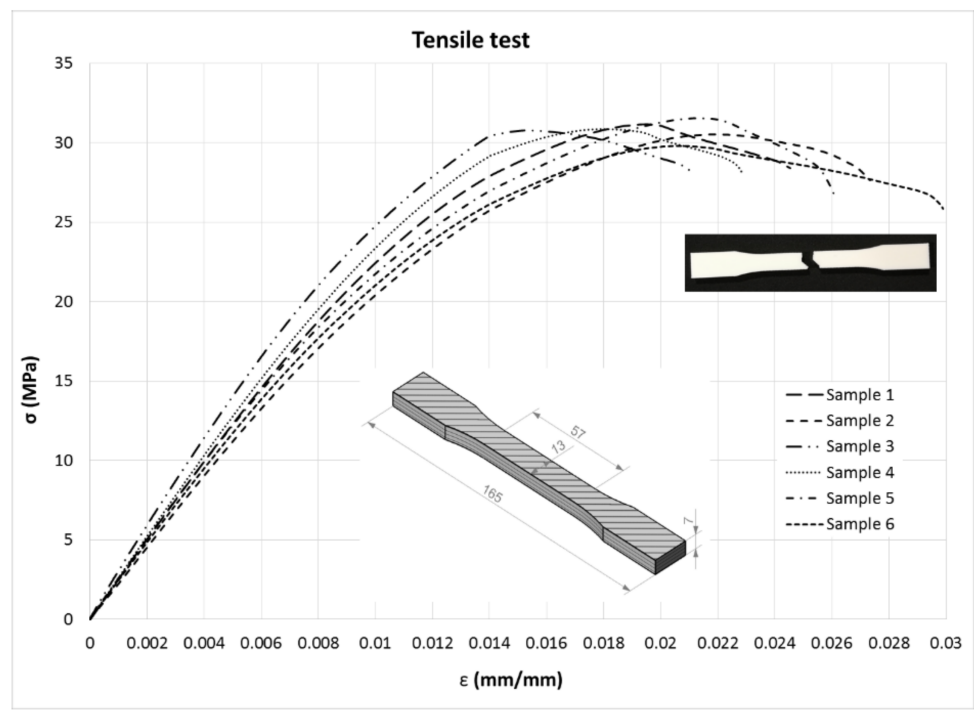

Figure 12. Tensile stress-strain curves.

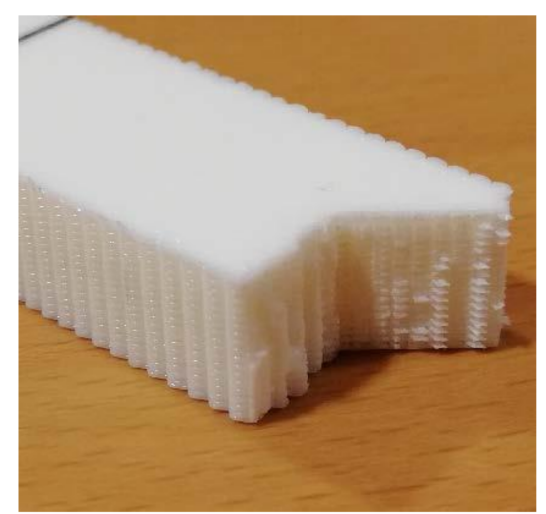

Figure 13. Aspect of brittle break of a tensile specimen by the minimum cross-section $-7 \times 19\left(\mathrm{~mm}^{2}\right)$.

The regression line of the initial linear part of the stress-strain curve was plotted, and the slope was taken as an E value (Figure 14).

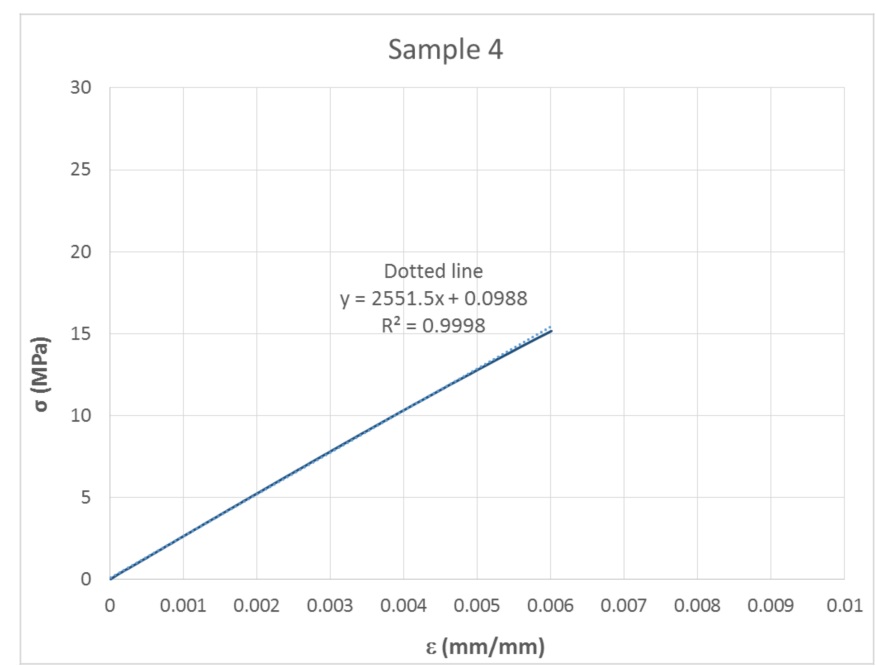

Figure 14. Regression line (dotted line) taken for calculation of modulus of elasticity (E). 
The Poisson's ratio $(v)$ was calculated from the data recorded by the two extensometers (linear and transverse). Figure 15 shows both deformations as a function of the applied load. With the slopes of these two straight lines, $v$ was calculated by dividing the values by each other.

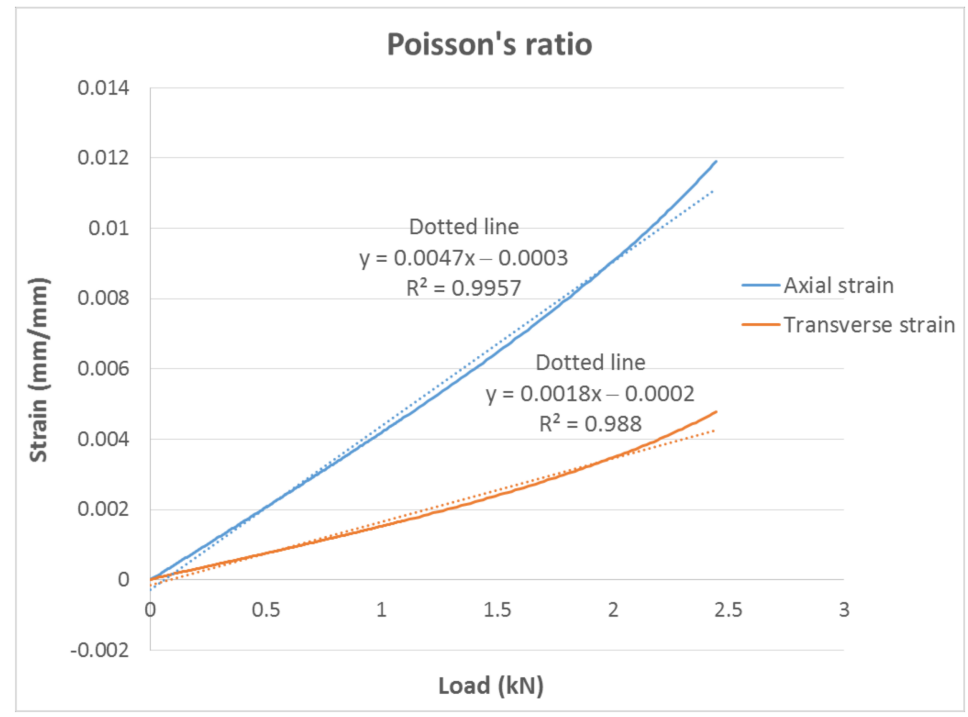

Figure 15. Regression lines (dotted lines) taken to calculate the Poisson's ratio. The continuous lines represent the strain measured by the extensometers as a function of the applied load.

Values of modulus of elasticity $(E)$, tensile strength $(\sigma)$, elongation at tensile strength $(\varepsilon)$ and Poisson's ratio $(v)$ derived from tensile tests are shown in Table 3, including mean and standard deviation (SD).

Table 3. Tensile properties obtained from tensile tests (ASTM D638).

\begin{tabular}{ccccc}
\hline Specimen & $\begin{array}{c}\text { Modulus of Elasticity } \\
\text { E (MPa) }\end{array}$ & $\begin{array}{c}\text { Tensile Strength } \\
\boldsymbol{\sigma}(\mathbf{M P a})\end{array}$ & $\begin{array}{c}\text { Elongation at } \boldsymbol{\sigma} \\
\boldsymbol{\varepsilon}(\mathbf{m m} / \mathbf{m m})\end{array}$ & $\begin{array}{c}\text { Poisson's Ratio } \\
\boldsymbol{v}\end{array}$ \\
\hline 1 & 2200.7 & 31.13 & 0.019 & - \\
2 & 2063.6 & 30.52 & 0.022 & - \\
3 & 2776.4 & 30.78 & 0.015 & - \\
4 & 2551.5 & 30.84 & 0.018 & 0.38 \\
5 & 2394.0 & 31.55 & 0.021 & 0.37 \\
6 & 2346.7 & 29.82 & 0.021 & 0.36 \\
Mean & 2388.8 & 30.77 & 0.019 & - \\
SD & 252.8 & 0.59 & 0.002 & - \\
\hline
\end{tabular}

\subsubsection{Compression Test Results}

Analogously to the methodology followed for the tensile tests, from the force-displacement data recorded during the test, the stress-strain curve was obtained. The graphs were adjusted by doing the toe compensation indicated by the Annex A1 of the ASTM D 695 standard [30]. It consisted of ignoring the initial "toe" region of the stress-strain curve, and obtaining the corrected zero point of the stress axis by intersecting the prolongation of the linear region of the curve with the stress axis.

The modulus of elasticity $(E)$, strength $(\sigma)$ and elongation $(\varepsilon)$ were determined from the data recorded during the test and subsequent calculations (Equation (1)).

It can be seen that, apparently, the strength increased in the plastic range of the material. This was because, as a result of compression, transformations occurred in the material, porosity was reduced, volume decreased and density increased. When the internal structure of the material changed, the load capacity changed. However, this did not affect the calculated parameters. 
Values of modulus of elasticity $(\mathrm{E})$, compressive yield point strength $(\sigma)$ and elongation at compressive yield point strength $(\varepsilon)$ are shown in Tables 4-6, including mean and standard deviation (SD). Since there were four series of test specimens in this case, it was deemed convenient to show the results separately (i.e., a table for each magnitude).

Table 4. Modulus of elasticity from compression test (ASTM D695).

\begin{tabular}{ccccc}
\hline \multirow{2}{*}{ Specimen } & \multicolumn{4}{c}{ E (MPa) } \\
\cline { 2 - 5 } & Prism $(\mathbf{L}=\mathbf{2 a})$ & Cylinder $(\mathbf{L}=\mathbf{2 D})$ & Prism $(\mathbf{L}=\mathbf{4 a})$ & Cylinder $(\mathbf{L}=\mathbf{4 D})$ \\
\hline 1 & 921.2 & 1076.1 & 1397.7 & 1472.4 \\
2 & 799.6 & 1077.6 & 1458.4 & 1463.8 \\
3 & 724.2 & 1099.2 & 1251.7 & 1516.2 \\
4 & 816.4 & 1113.5 & 1453.0 & 1563.0 \\
5 & 802.7 & 1097.6 & 1355.3 & 1564.5 \\
6 & 802.4 & 1123.3 & 1304.9 & 1549.4 \\
Mean & 811.1 & 1097.9 & 1370.2 & 1521.5 \\
SD & 63.2 & 18.9 & 82.4 & 45.0 \\
\hline
\end{tabular}

Table 5. Compressive yield point strength from compression test (ASTM D695).

\begin{tabular}{ccccc}
\hline \multirow{2}{*}{ Specimen } & \multicolumn{4}{c}{$\boldsymbol{\sigma}(\mathbf{M P a})$} \\
\cline { 2 - 5 } & Prism (L = 2a) & Cylinder (L = 2D) & Prism (L = 4a) & Cylinder (L = 4D) \\
\hline 1 & 30.06 & 41.17 & 32.57 & 42.49 \\
2 & 25.97 & 40.66 & 39.79 & 41.56 \\
3 & 24.25 & 42.58 & 28.83 & 43.64 \\
4 & 27.57 & 42.82 & 40.10 & 45.52 \\
5 & 26.58 & 41.78 & 31.71 & 45.14 \\
6 & 26.79 & 42.13 & 31.10 & 44.27 \\
Mean & 26.87 & 41.86 & 34.02 & 43.77 \\
SD & 1.92 & 0.83 & 4.76 & 1.53 \\
\hline
\end{tabular}

Table 6. Elongation at compressive yield point strength from compression test (ASTM D695).

\begin{tabular}{ccccc}
\hline \multirow{2}{*}{ Specimen } & \multicolumn{4}{c}{$\varepsilon(\mathbf{m m} / \mathbf{m m})$} \\
\cline { 2 - 5 } & Prism $(\mathbf{L}=\mathbf{2 a})$ & Cylinder $(\mathrm{L}=\mathbf{2 D})$ & Prism $(\mathbf{L}=\mathbf{4 a})$ & Cylinder $(\mathbf{L}=\mathbf{4 D})$ \\
\hline 1 & 0.041 & 0.043 & 0.026 & 0.042 \\
2 & 0.039 & 0.043 & 0.035 & 0.038 \\
3 & 0.039 & 0.044 & 0.029 & 0.041 \\
4 & 0.038 & 0.043 & 0.036 & 0.042 \\
5 & 0.038 & 0.043 & 0.031 & 0.043 \\
6 & 0.039 & 0.042 & 0.032 & 0.033 \\
Mean & 0.039 & 0.043 & 0.031 & 0.040 \\
SD & 0.001 & 0.000 & 0.004 & 0.004 \\
\hline
\end{tabular}

Figure 16a,b shows the compressive response at medium levels of deformation for short specimens. For high levels of deformation, the long specimens failed by global buckling (Figure 16c,d), and the failure pattern of the short specimens was a barrel shape (Figure 17). 


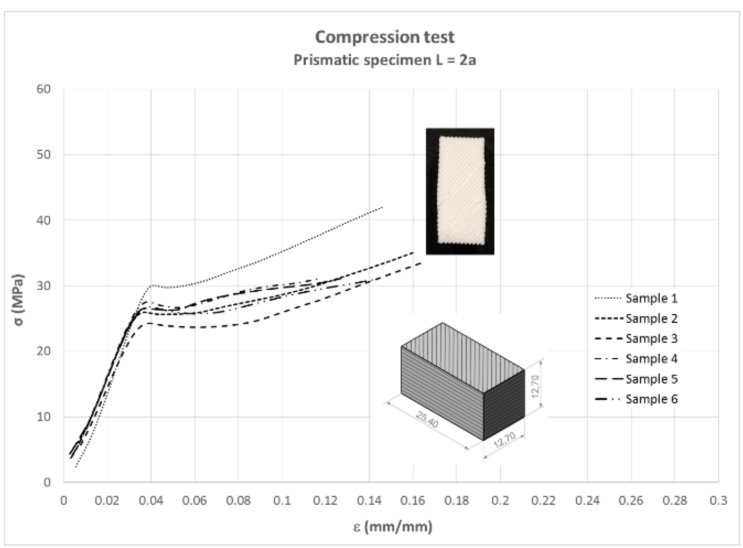

(a)

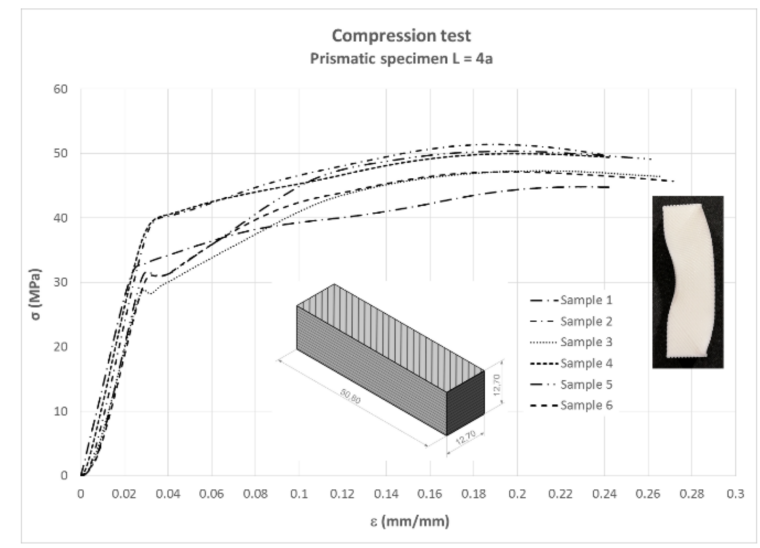

(c)

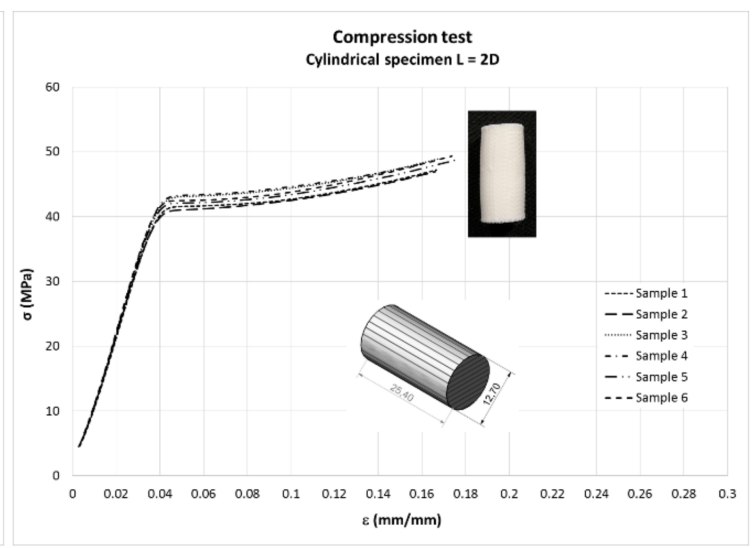

(b)

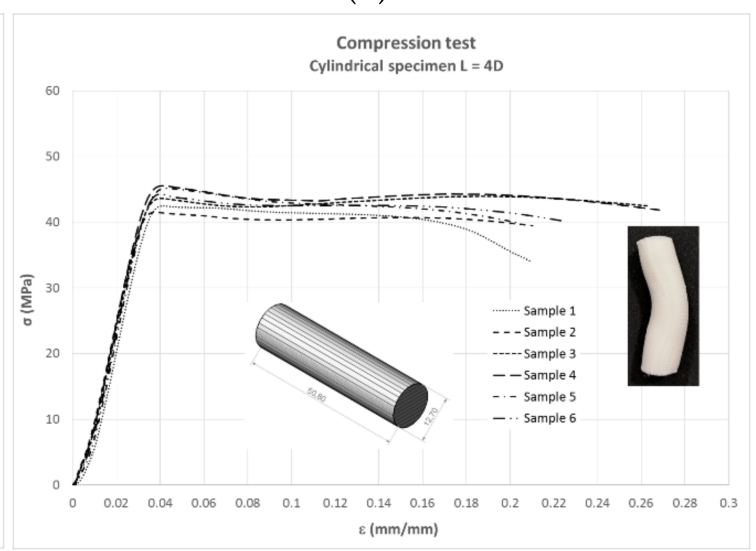

(d)

Figure 16. Compressive stress-strain diagrams: prismatic short shape (a), cylindrical short shape (b), prismatic long shape (c) and cylindrical long shape (d).

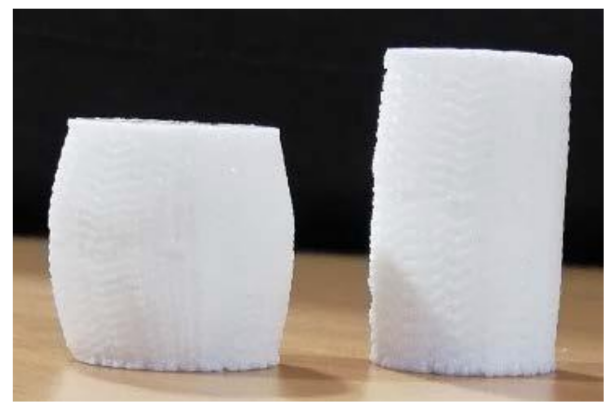

Figure 17. Samples tested until different levels of deformation.

\subsubsection{Bending Test Results}

Stress-strain curves, overlapped for all specimens, are shown in Figure 18. The maximum value of $\sigma_{\mathrm{f}}$ was taken as flexural strength, and $\varepsilon_{\mathrm{f}}$ was the respective deformation.

Values of the tangent modulus of elasticity $\left(E_{B}\right)$, flexural stress $\left(\sigma_{f}\right)$ and flexural strain $\left(\varepsilon_{f}\right)$ are shown in Table 7 , including mean and standard deviation (SD). Flexural stress $\left(\sigma_{\mathrm{f}}\right)$ and flexural strain $\left(\varepsilon_{\mathrm{f}}\right)$ were calculated using Equation (4). According to the standard, the modulus of elasticity in bending $\left(\mathrm{E}_{\mathrm{B}}\right)$ was calculated by means of Equation (5):

$$
E_{B}=\frac{L^{3} \frac{P}{\delta}}{4 b h^{3}}=\frac{P L^{3}}{48 \delta I}
$$


where:

$I$ is the moment of inertia of the cross-section $\left(\mathrm{mm}^{4}\right)$.

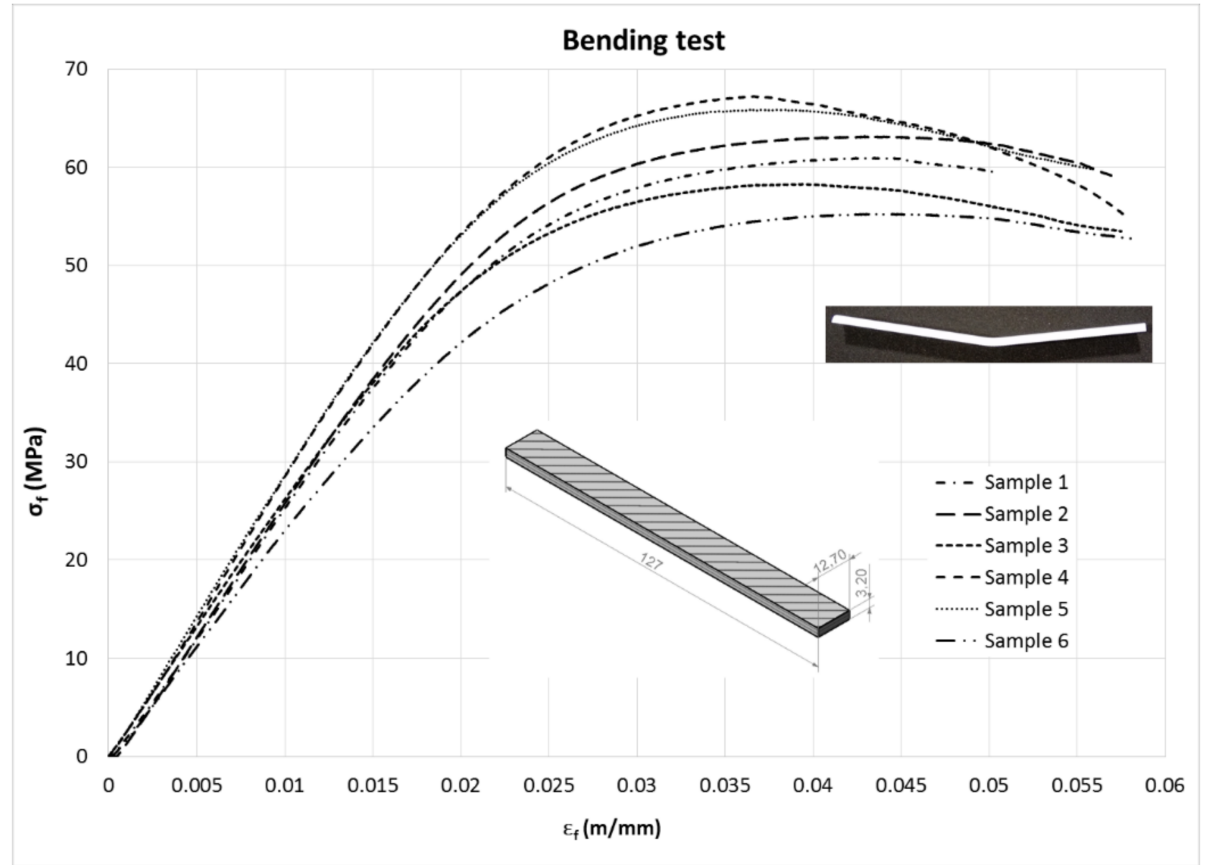

Figure 18. Flexural stress versus flexural strain curves.

Table 7. Flexural properties from three-point bending test (ASTM D790).

\begin{tabular}{cccc}
\hline Specimen & E $_{\mathbf{B}}(\mathbf{M P a})$ & $\left.\boldsymbol{\sigma}_{\mathbf{f}} \mathbf{( M P a}\right)$ & $\varepsilon_{\mathbf{f}}(\mathbf{m m} / \mathbf{m m})$ \\
\hline 1 & 2603.0 & 60.92 & 0.042 \\
2 & 2657.4 & 63.19 & 0.043 \\
3 & 2572.1 & 58.34 & 0.039 \\
4 & 2900.2 & 67.26 & 0.036 \\
5 & 2859.0 & 65.87 & 0.036 \\
6 & 2265.4 & 55.22 & 0.043 \\
Mean & 2642.8 & 61.80 & 0.040 \\
SD & 229.0 & 4.57 & 0.003 \\
\hline
\end{tabular}

\subsection{Numerical Testing Results (FE Analysis)}

Figures 19-22 show the normal stress plots for each of the four specimen types: short prismatic (Figure 19), short cylindrical (Figure 20), long prismatic (Figure 21) and long cylindrical (Figure 22).

There were no significant differences in the influence of the shape of the cross-section.

It can be perceived that longer samples exhibited a quasi-uniform distribution of stresses over a wide intermediate length, while shorter samples had hardly a uniform distribution in the intermediate cross-section, which means that the boundary conditions at the ends of the specimen had more influence on shorter samples. This effect was more notorious in the prismatic rather than the cylindrical specimens. 


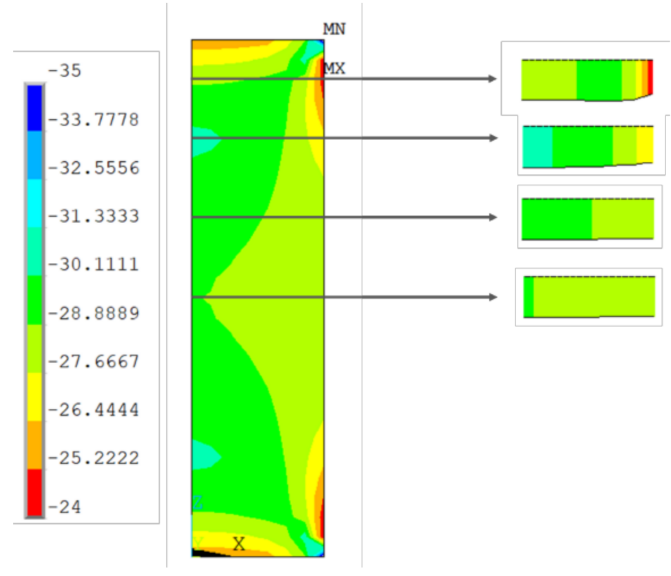

Figure 19. Distribution of normal compressive stresses $\left(\mathrm{N} / \mathrm{mm}^{2}\right)$ for the middle section of the symmetry plane. Short prismatic specimen.
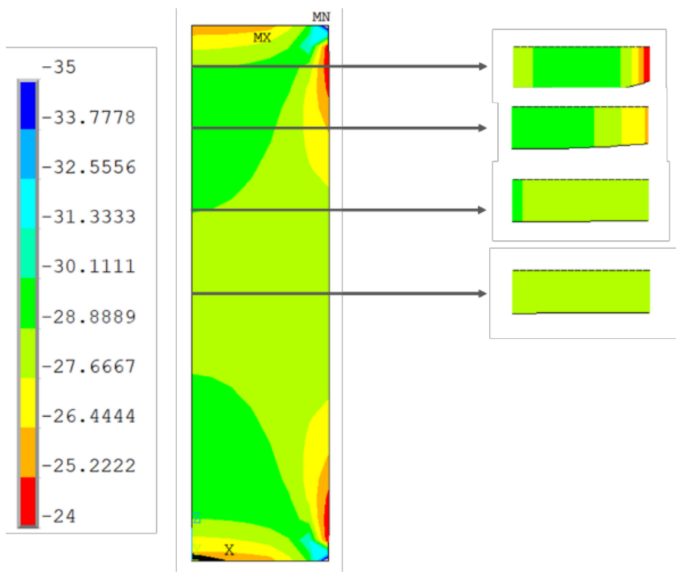

Figure 20. Distribution of normal compressive stresses $\left(\mathrm{N} / \mathrm{mm}^{2}\right)$ for the middle section of the symmetry plane. Short cylindrical specimen.

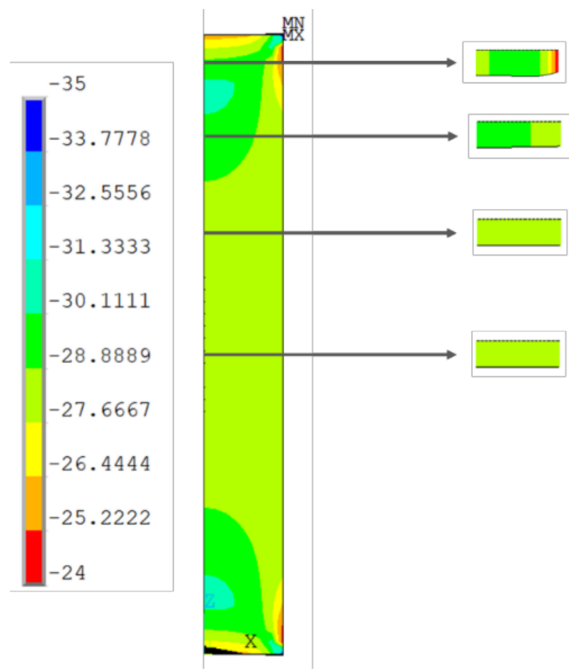

Figure 21. Distribution of normal compressive stresses $\left(\mathrm{N} / \mathrm{mm}^{2}\right)$ for the middle section of the symmetry plane. Long prismatic specimen. 


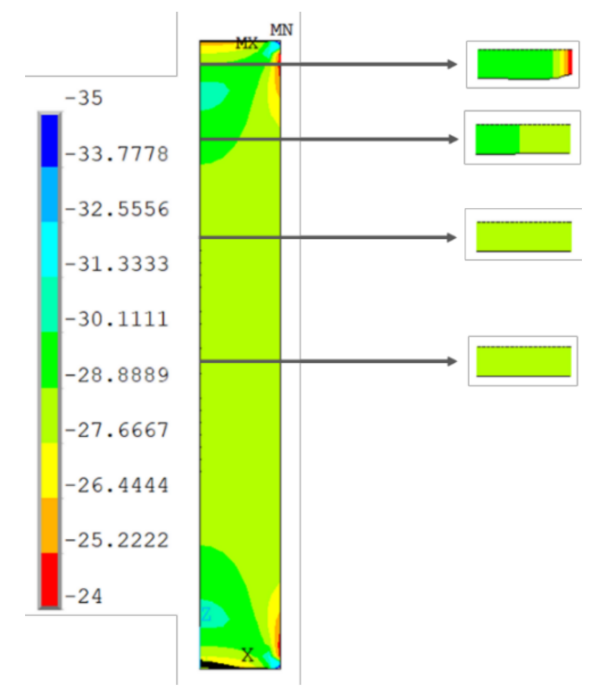

Figure 22. Distribution of normal compressive stresses $\left(\mathrm{N} / \mathrm{mm}^{2}\right)$ for the middle section of the symmetry plane. Long cylindrical specimen.

\section{Discussion of Results}

\subsection{Experimental Tensile, Compression and Bending Tests}

In order to compare the results between the three types of tests, in the case of the compression test, the average of the long specimens was taken, given that the standard recommends this when determining the modulus of elasticity.

The second, third and fourth columns of Table 8 summarize the modulus of elasticity (E), strength $(\sigma)$ and elongation $(\varepsilon)$ found for each type of test, respectively, while the last two columns capture mechanical properties of processed PLA by injection [2,22]. Figures $23-25$ show the results in bar graph format.

Table 8. Summary table of the mechanical properties of the three tests.

\begin{tabular}{cccccc}
\hline Test & E (MPa) & $\boldsymbol{\sigma} \mathbf{( M P a )}$ & $\varepsilon(\mathbf{m m} / \mathbf{m m})$ & Farah et al. [2] & *Song et al. [22] \\
\hline Compression & 1445.9 & 38.89 & 0.036 & - & $3200 \div 3880,70.80 \div 71.94,-$ \\
Tensile & 2388.8 & 30.77 & 0.019 & $3700,65.6,0.04$ & $3430 \div 3680,29.79 \div 46.76,-$ \\
Flexural & 2642.8 & 61.80 & 0.040 & - & - \\
\hline
\end{tabular}

$\left({ }^{*}\right)$ depending on the strain rate.

It can be seen that the highest modulus of elasticity was the flexural modulus, with a value of $2640 \mathrm{MPa}$, followed by the tensile modulus with $2390 \mathrm{MPa}$. This was not a significant difference; however, the value of the modulus of elasticity in compression was $1445 \mathrm{MPa}$, approximately $40 \%$ lower than the previous two. This scenario would be anomalous from the point of view of a bimodular behaviour, as it should be an intermediate value between them. In effect, using the calculation method described in [23], given the elastic modules of $2515 \mathrm{MPa}$ in tension and $1445 \mathrm{MPa}$ in compression, the modulus in three-point bending should be around $1836 \mathrm{MPa}$ (the effect of shear deformation in the specimen was taken into account), considerably lower than the observed value of $2575 \mathrm{MPa}$. 


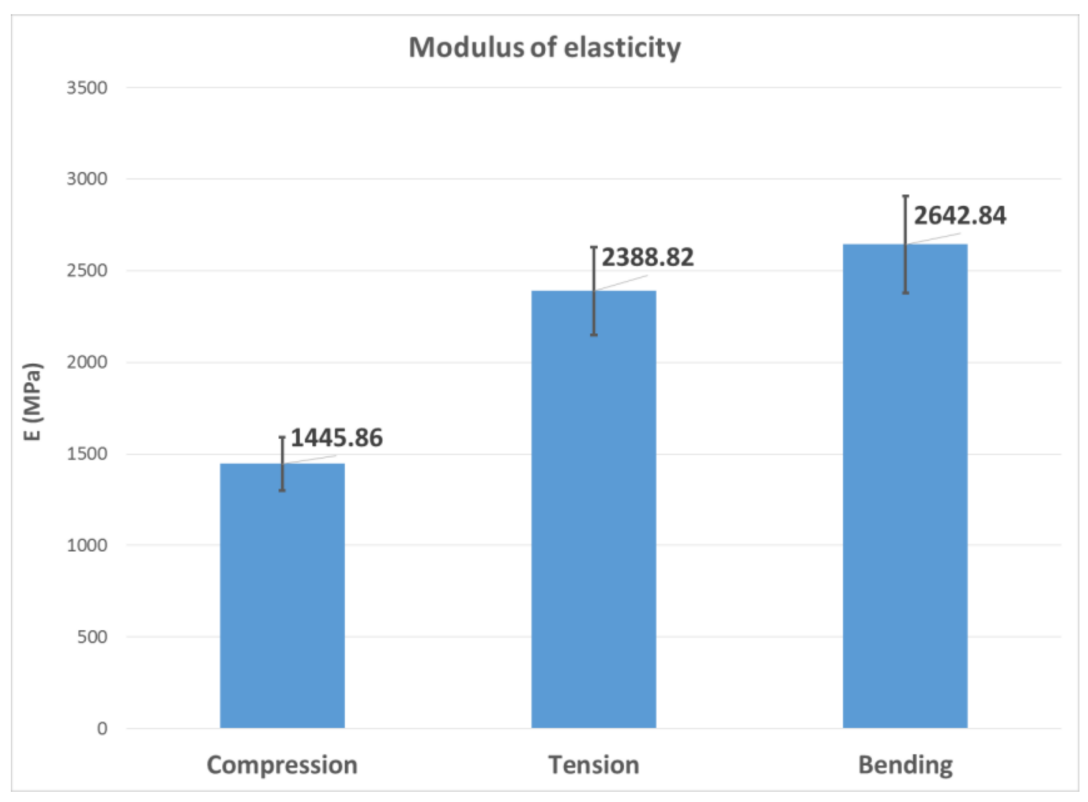

Figure 23. Bar graph with the mean value of the E variable.

This apparent anomaly was investigated by re-evaluating the values of the elastic modules in order to find out the causes of the discrepancy. The following corrections were made to the data sets of the three tests:

- The nominal definitions of stress (force per unit of initial area) and strain (increase in length per unit of the initial length of the extensometer) were changed to their true values (true stress-force per unit of area of the deformed section; true strain—logarithmic strain), assuming the constant volume hypothesis (the volume of the material remains constant during deformation), in order to consider the effect of the variation of the cross section during the tensile and compression tests.

- The non-linearity in the initial phase of the stress-strain curve in the compression test was corrected for the long samples $(\mathrm{L}=4 \mathrm{D}$ and $\mathrm{L}=4 \mathrm{a}$ ) by performing the toe compensation indicated in annex A1 of standard D695-02a. The parallelism between the faces of the samples was critical. This effect was more pronounced in short samples than in long samples.

- Calculations of the initial elastic modulus were carried out for the three types of tests (tension, compression and bending) considering the linear part of the stress-strain curves (strain from 0 to $0.004 \mathrm{~mm} / \mathrm{mm}$ ).

Table 9 lists the new elastic modulus values found after these adjustments.

Table 9. Summary of re-evaluated modulus of elasticity.

\begin{tabular}{ccccc}
\hline \multirow{2}{*}{ Specimen } & \multicolumn{4}{c}{ E (MPa) } \\
\cline { 2 - 5 } & Tension & Compression L = 4D & Compression L = 4a & Bending \\
\hline 1 & 2497 & 1405 & 1405 & 2455 \\
2 & 2282 & 1362 & 1375 & 2666 \\
3 & 2845 & 1485 & 1225 & 2679 \\
4 & 2599 & 1507 & 1441 & 2699 \\
5 & 2478 & 1452 & 1353 & 2601 \\
6 & 2388 & 1459 & 1276 & 2349 \\
Mean & 2515 & 1445 & 1346 & 2575 \\
SD & 194 & 53 & 81 & 142 \\
\hline
\end{tabular}


The new values obtained showed less dispersion, both between samples of the same test and between the different types of cross-sections in the compression tests of long specimens.

As can be seen, the values of the tensile and bending modules were now more similar to those shown in Figure 23, although the mean bending value was slightly higher than the mean tensile value.

However, the results obtained from the three standard tests were still inconsistent with bimodular behaviour. This inconsistency is mainly attributed to differences in sample geometry, which also generates process differences, and to different strain rates in the standard tests. Since these are uniaxial tests, and the print layers are very thin, the effect of anisotropy was considered to be minor.

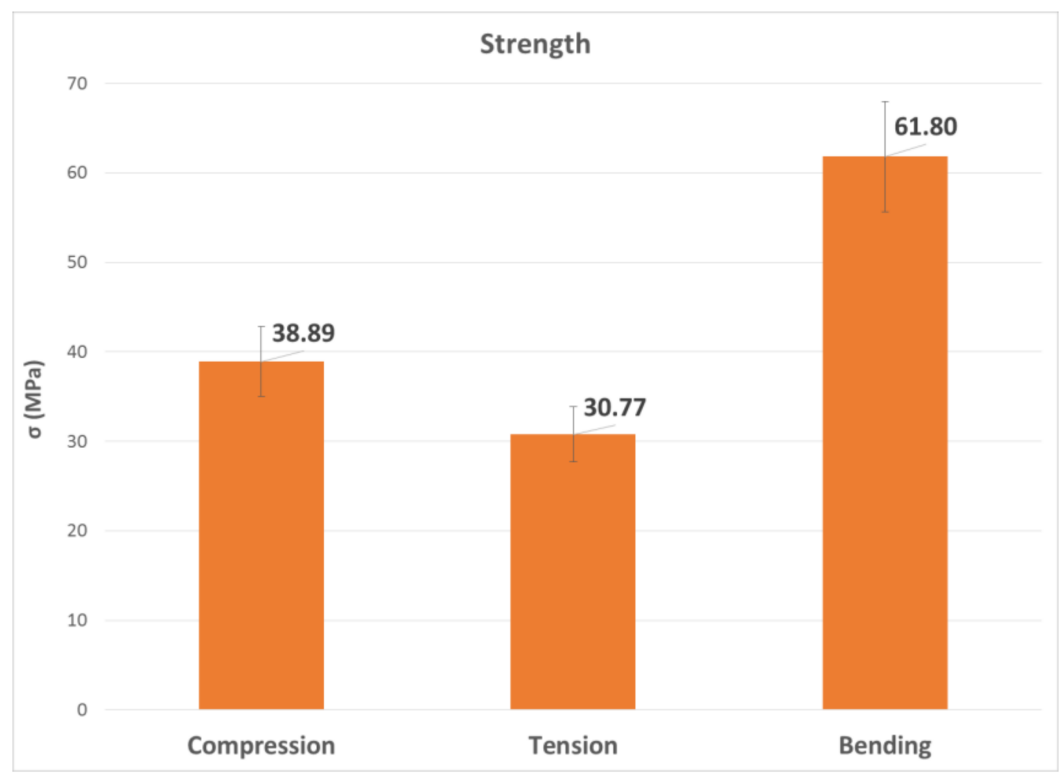

Figure 24. Bar graph with the mean value of the $\sigma$ variable.

The most remarkable thing about graphics related to strength is that the flexural value was considerably higher than the other two, $60 \%$ higher than the compressive strength and twice as high as the tensile strength, which is clearly the lowest.

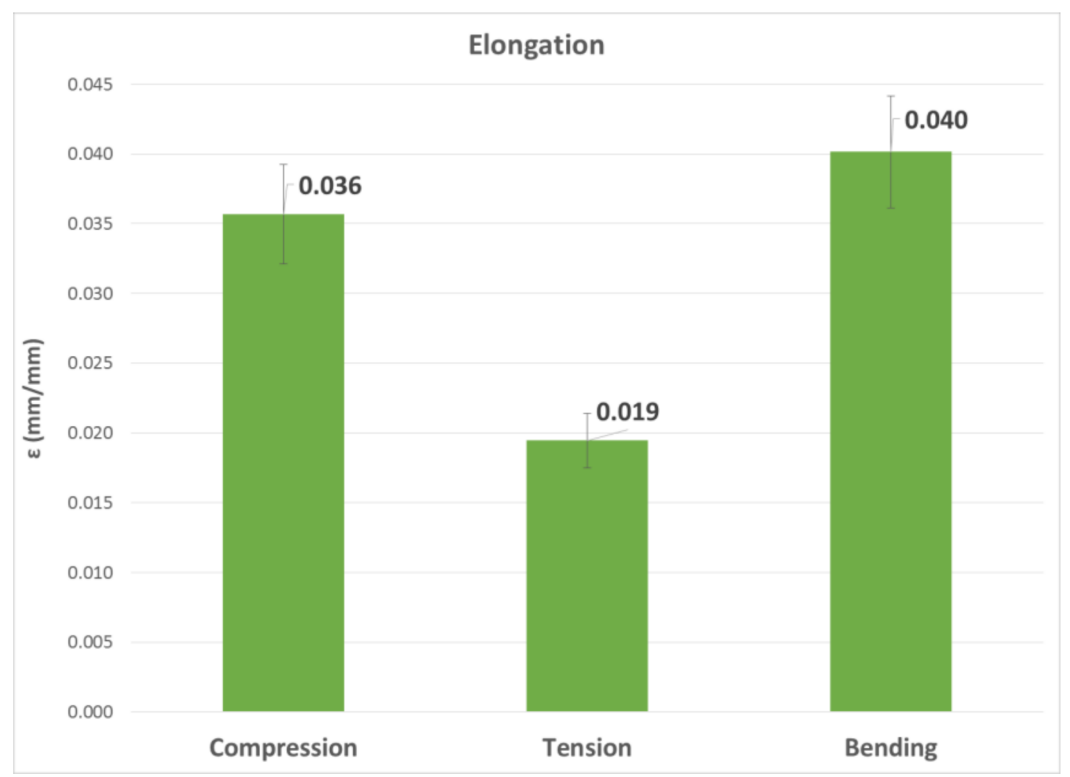

Figure 25. Bar graph with the mean value of the $\varepsilon$ variable. 
Finally, the graphs of the elongation values were compared. As above, the highest value corresponded to the bending test, followed by compression, although they did not show such a significant difference. The elongation for the tensile test was the lowest.

These results are shown here in summary:

$$
\begin{aligned}
& E_{\text {bending }} \approx E_{\text {tensile }} \gg E_{\text {compression }} \\
& \sigma_{\text {bending }} \gg \sigma_{\text {compression }}>\sigma_{\text {tensile }} \\
& \varepsilon_{\text {bending }} \gtrsim \varepsilon_{\text {compression }} \gg \varepsilon_{\text {tensile }}
\end{aligned}
$$

The results obtained from the tests of the four series of compression specimens, two lengths and two cross-section shapes, are analysed in the following Section.

\subsection{Specific Analysis of the Compression Test}

As can be seen in Figure 26, the modulus of elasticity of long specimens was considerably higher regardless of the cross-section shape. This result is consistent with [34]: Young's modulus decreases when the diameter:length ratio increases. In the case of cylindrical specimens, the value for long specimens was $40 \%$ higher, being $70 \%$ higher in prismatic specimens. On the other hand, the cylinder shape also had a higher value within each length. Thus, the highest value was that of long-cylinder specimens.

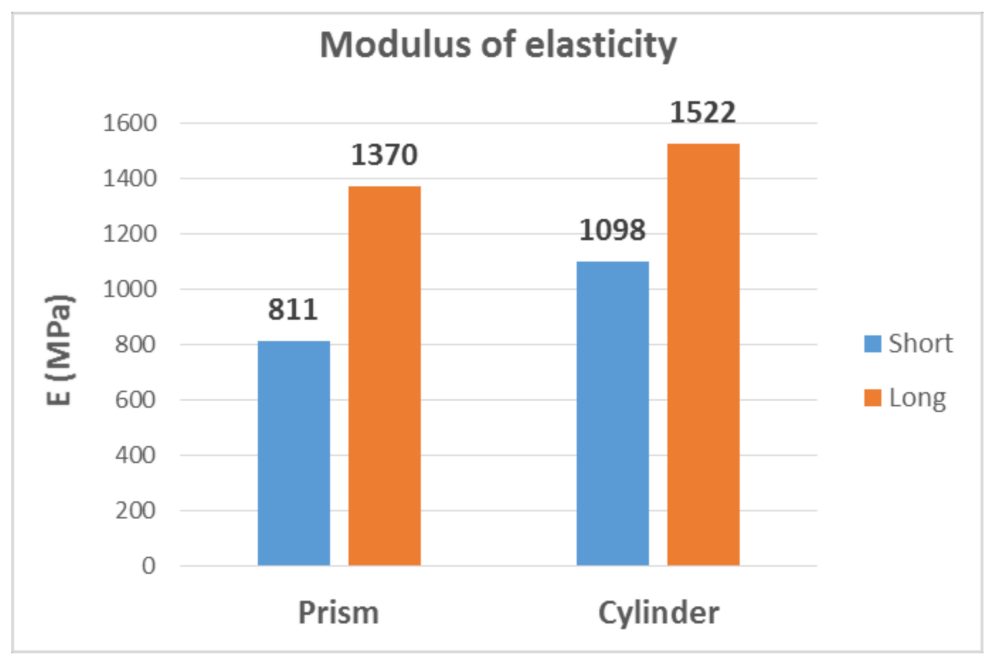

Figure 26. Comparison of modulus of elasticity in compression tests.

In the last row of Table 4, the dispersions of the values of the compressive modulus of elasticity (in $\%)$ were calculated for each type of sample. All values are within the acceptable range of variation when the modulus of elasticity is measured, as this is a parameter that tends to present higher dispersion than other ones (e.g., breaking stresses). Some conclusions can be drawn from Table 4:

(a) It was observed that the rectangular samples (2a and 4a) showed higher dispersion (in \%) than the cylindrical ones (2D and 4D). Therefore, it is recommended the use of cylindrical specimens to determine the modulus $\mathrm{E}$.

(b) The difference between the mean value of the modulus of elasticity obtained from samples $4 \mathrm{D}$ and $4 \mathrm{a}$ was $11.0 \%$, whereas the difference between the mean value obtained from the 2D and $2 \mathrm{a}$ samples was $35.3 \%$.

By combining reasoning a) and b), it is concluded that the most appropriate sample type to determine the modulus $\mathrm{E}$ is the $\mathrm{L}=4 \mathrm{D}$ type. 
In addition to the dispersion inherent in a compression test, the influence of two other factors was identified and analysed:

(c) The flexibility of the testing machine caused an increase in the displacement between the compression plates, which implied obtaining an elastic modulus lower than the real modulus of the material. Although the compression test standard ASTM D695-02a did not provide for correction for this effect, the actual modulus E can be calculated from the measured modulus E' by using the following Equation:

$$
E=\frac{L}{\frac{L}{E^{\prime}}-\frac{A}{K_{M}}},
$$

where:

$L$ is the length of the specimen;

$A$ is the area of the cross-section;

$K_{M}$ is the rigidity of the testing machine.

Table 10 shows the values initially determined for each type of specimen together with the values achieved after making the correction for the flexibility of the testing machine, as well as the variation (in \%).

Table 10. Influence of the flexibility of the testing machine.

\begin{tabular}{cccc}
\hline Specimen & $\begin{array}{c}\mathbf{E}^{\prime} \text { (Measured) } \\
\mathbf{( M P a )}\end{array}$ & $\begin{array}{c}\text { E (Real) } \\
\mathbf{( M P a )}\end{array}$ & $\begin{array}{c}\text { Variation } \\
\mathbf{( \% )}\end{array}$ \\
\hline $\mathrm{L}=2 \mathrm{a}$ & 811.1 & 938 & 16 \\
$\mathrm{~L}=2 \mathrm{D}$ & 1097.9 & 1283 & 17 \\
$\mathrm{~L}=4 \mathrm{a}$ & 1370.2 & 1547 & 13 \\
$\mathrm{~L}=4 \mathrm{D}$ & 1521.5 & 1690 & 11 \\
\hline
\end{tabular}

It was observed that the effect of the flexibility of the testing machine was less for long specimens (4a and 4D). This is an additional reason for using long specimens to determine the modulus E.

(d) Friction between the sample and the load plates of the machine limited the effect of Poisson at the ends of the sample, and caused a barrel shape, which altered the assumed uniform distribution of stresses and deformations, thus increasing the apparent elastic modulus. The barrel shape was observed in some of the specimens (see Figure 17). To verify the influence of this effect on the Young's modulus, two finite element simulations of the compression tests were performed. In the first one, it was assumed that there was no friction, and in the second one, the friction completely blocked the sliding between both surfaces in contact. The sample stiffness variation (which is proportional to the Young's modulus) is shown in Table 11, where the percentage compression stiffness variation is expressed with regard to the frictionless model.

Table 11. Variation of the stiffness with respect to the model without friction, obtained by FEA.

\begin{tabular}{cc}
\hline Specimen & Variation in Stiffness (\%) \\
\hline $\mathrm{L}=2 \mathrm{a}$ & 4.17 \\
$\mathrm{~L}=2 \mathrm{D}$ & 3.56 \\
$\mathrm{~L}=4 \mathrm{a}$ & 2.08 \\
$\mathrm{~L}=4 \mathrm{D}$ & 1.78 \\
\hline
\end{tabular}

It was noticed that the influence of the coefficient of friction between the specimen and the test machine plates was low, being lower for long specimens (4a and 4D). This is an additional argument for using long specimens to determine the modulus E. 
In the values of compressive strength (Figure 27), it is observed that cylindrical samples had higher strength values, regardless of the length of the sample. The differences between them were not as noticeable as in the case of the modulus of elasticity.

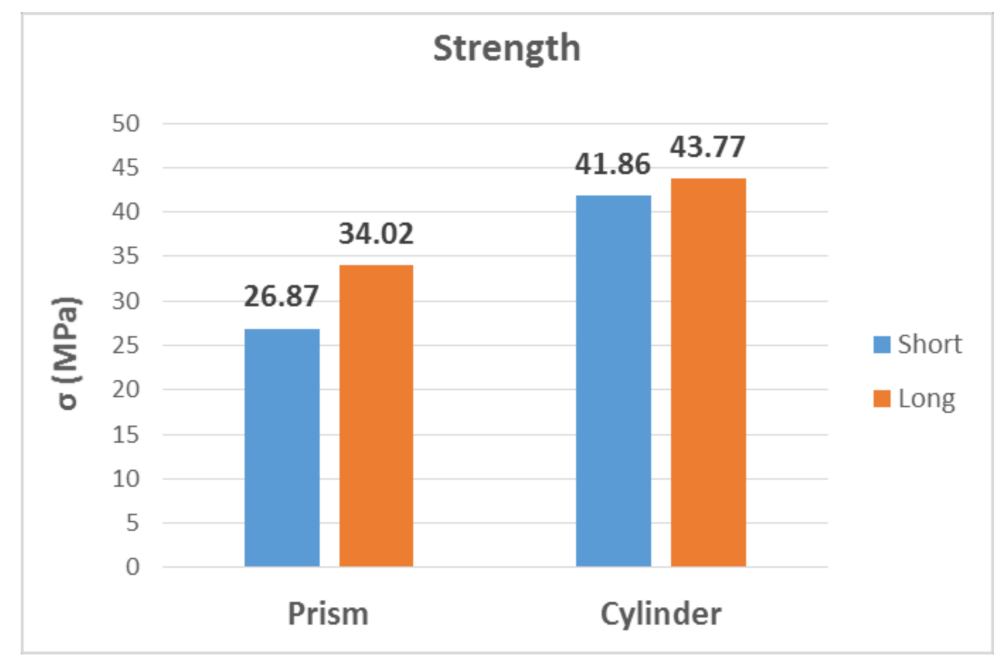

Figure 27. Comparison of compressive strength.

Finally, the elongation (Figure 28) obtained for cylindrical samples was also slightly higher than that obtained for prismatic samples. In addition, higher values were found in the short samples than in the long ones. However, in the case of elongation, the differences were less meaningful than in the case of the modulus of elasticity and strength.

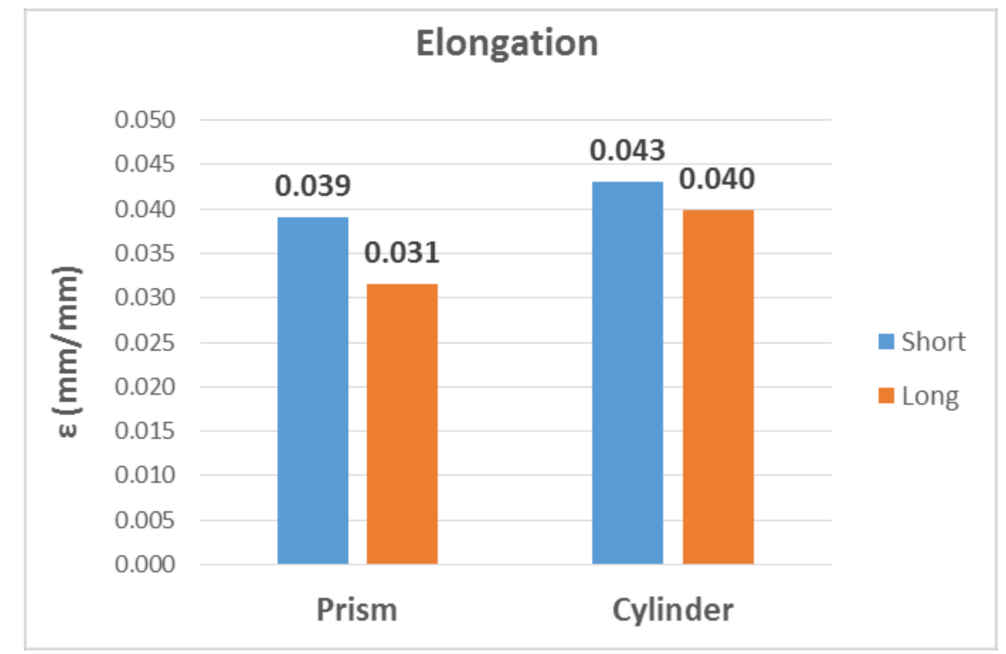

Figure 28. Comparison of elongation in compression tests.

These results are summarized in the following expressions:

$$
\begin{aligned}
& E_{\text {Cylinder }}>E_{\text {Prism }} \text { and } E_{\text {Long }} \gg E_{\text {Short }} \\
& \sigma_{\text {Cylinder }}>\sigma_{\text {Prism }} \text { and } \sigma_{\text {Long }} \approx \sigma_{\text {Short }} \\
& \varepsilon_{\text {Cylinder }}>\varepsilon_{\text {Prism }} \text { and } \varepsilon_{\text {Long }}<\varepsilon_{\text {Short }}
\end{aligned}
$$




\section{Conclusions}

The mechanical properties of PLA manufactured by FDM were determined under tensile, compressive and flexural stresses. The results obtained are quite consistent, considering the low dispersion of results within each group of specimens and in comparison with available data.

However, the results obtained in this work show that PLA has a double asymmetry in its tensile and compressive behaviours: On the one hand the asymmetry in strength, and on the other hand asymmetry in the constitutive behaviour, which suggests the need to treat this material by means of a bimodular elasticity model.

Nevertheless, characterisation based on standard tests presents significant difficulties when its purpose goes beyond its application to quality control tasks, such as numerical simulation.

The behaviour of 3D-printed materials is highly sensitive to process factors and, in the case of polymeric materials, also to the effect of different strain rates applied in each test. This makes it difficult to achieve a consistent characterisation of the elastic constants among the various types of standard tests available today, even when taking into account that the different dimensions and shapes of the specimens in each test can cause process differences that affect in the measured properties.

For this reason, it is necessary to define a new characterisation procedure that allows obtaining a consistent set of elastic constants, with the minimum number of tests possible, especially adapted to bimodular materials. This result would be of great interest for carrying out simulations of the structural behaviour of 3D printed parts. Recently, Mazzanti et al. [40] concluded there is no recognised international standard governing the characterisation of the tensile, compressive or flexural properties of 3D-printed materials. The current standards are those used for the characterisation of bulk polymeric materials. In this case, the geometric characteristics are standardized through the concepts of stress and strain, but in the case of 3D printing, this is difficult because the specimen is actually a structure, not a material.

With respect to the compression test, it has been demonstrated that there is less variability of results in cylindrical specimens than in prismatic specimens (probably a result of the manufacturing process, since at the corners of the prismatic shapes the printing head can deposit excess material). In addition, when determining the modulus of elasticity, it is confirmed that, following the recommendation of the ASTM D695 standard, the longer specimens provide results that are more consistent.

The need to perform compression tests to characterise the elastic modulus to compression should be reconsidered. This could be consistently deduced using a bimodular model from the bending test, through the flexural modulus, or also from the shear test, through the transverse modulus of elasticity $\mathrm{G}$, thus avoiding the uncertainties associated with the compression test.

The simulation of the compression test shows that the model is sensitive to the boundary conditions applied at the ends of the specimen (friction, etc.). Despite the introduction of geometric non-linearity in the analysis (GNA), this is not enough to correctly reproduce the actual behaviour of the material in a coherent way.

Author Contributions: Conceptualization, M.-M.P.-A., F.R.-F. and X.A.-G.; methodology, M.-M.P.-A and F.R.-F.; software, J.B.-B.; formal analysis, X.A.-G.; resources, E.P.-G. and I.B.-C.; writing-original draft preparation, M.-M.P.-A.; writing-review and editing, F.R.-F., X.A.-G., J.B.-B., I.B.-C. and E.P.-G.; supervision, M.-M.P.-A. All authors have read and agreed to the published version of the manuscript.

Funding: This research has been funded by the Spanish Ministry of Economy, Industry and Competitiveness; Grant Number DPI2016-80345-R.

Acknowledgments: The authors thank Marina Blasco, Bachelor of Mechanical Engineering, for her important contribution to the work. They also thank Ramón Casado-López and Francesc-Joaquim García-Rabella for their help with experimental tests.

Conflicts of Interest: The authors declare no conflict of interest. 


\section{References}

1. Wohlers. Wohlers Report 2014: Additive Manufacturing and 3D Printing State of the Industry, Annual Worldwide Progress Report; Wohlers Associates Inc.: Fort Collins, CO, USA, 2014.

2. Farah, S.; Anderson, D.G.; Langer, R. Physical and mechanical properties of PLA, and their functions in widespread applications-A comprehensive review. Adv. Drug Deliv. Rev. 2016, 107, 367-392. [CrossRef] [PubMed]

3. Chen, L.; He, Y.; Yang, Y.; Niu, S.; Ren, H. The research status and development of additive manufacturing technology. Int. J. Adv. Manuf. Technol. 2017, 89, 3651-3660. [CrossRef]

4. Srivastava, V.K. A Review on Advances in Rapid Prototype 3D Printing of Multi-Functional Applications. Sci. Technol. 2017, 7, 4-24.

5. Chiulan, I.; Frone, A.N.; Brandabur, C.; Panaitescu, D.M. Recent Advances in 3D Printing of Aliphatic Polyesters. Bioengineering 2018, 5, 2. [CrossRef] [PubMed]

6. Dizon, J.R.C.; Espera, A.H., Jr.; Chen, Q.; Advincula, R.C. Mechanical characterization of 3d-printed polymers (Review). Addit. Manuf. 2018, 20,44-67. [CrossRef]

7. Popescu, D.; Zapciu, A.; Amza, C.; Baciu, F.; Marinescu, R. FDM process parameters influence over the mechanical properties of polymer specimens: A review. Polym. Test 2018, 69, 157-166. [CrossRef]

8. Tymrak, B.M.; Kreiger, M.; Pearce, J.M. Mechanical properties of components fabricated with open-source 3-D printers under realistic environmental conditions. Mater. Des. 2014, 58, 242-246. [CrossRef]

9. Chacón, J.M.; Caminero, M.A.; García-Plaza, E.; Núñez, P.J. Additive manufacturing of PLA structures using fused deposition modelling: Effect of process parameters on mechanical properties and their optimal selection. Mater. Des. 2017, 124, 143-157. [CrossRef]

10. Innofil. Comparable data sheet Innofil3D filaments. In Overview Mechanical Properties of Printed Test Specimens; Basf: Emmen, the Netherlands; Available online: https:/www.innofil3d.com/wp-content/uploads/2016/06/ Pro1_Comparison_Sheet_small.pdf (accessed on 6 May 2019).

11. 3Faktur. FDM/FFF Materials: ABS and PLA; 3Faktur GmbH: Jena, Germany; Available online: https: //3faktur.com/en/3d-printing-materials-technologies/fdm-materials-pla-and-abs/ (accessed on 6 May 2019).

12. MakerBot. PLA and ABS Strength Data; MakerBot Industries LLC: New York, NY, USA; Available online: http: //download.makerbot.com/legal/MakerBot_R_PLA_and_ABS_Strength_Data.pdf (accessed on 6 May 2019).

13. SD3D. PLA Technical Data Sheet; SD3D Printing, Inc.: San Diego, CA, USA; Available online: https: //www.sd3d.com/wp-content/uploads/2017/06/MaterialTDS-PLA_01.pdf (accessed on 22 July 2017).

14. Ultimaker. PLA Technical Data Sheet; Ultimaker BV: Utrecht, the Netherlands; Available online: https: //ultimaker.com/download/74599/UM180821\%20TDS\%20PLA\%20RB\%20V10.pdf (accessed on 6 May 2019).

15. Lanzotti, A.; Grasso, M.; Staiano, G.; Martorelli, M. The impact of process parameters on mechanical properties of parts fabricated in PLA with an open-source 3-D printer. Rapid Prototyp. J. 2015, 21, 5. [CrossRef]

16. Ahmed, M.; Islam, M.; Vanhoose, J.; Rahman, M. Comparisons of Elasticity Moduli of Different Specimens Made Through Three Dimensional Printing. 3D Print Addit. Manuf. 2017, 4, 105-109. [CrossRef]

17. Cantrell, J.T.; Rohde, S.; Damiani, D.; Guranani, R.; DiSandro, L.; Anton, J.; Young, A.; Jerez, A.; Steinbach, D.; Kroese, C.; et al. Experimental characterization of the mechanical properties of 3D-printed ABS and polycarbonate parts. Rapid Prototyp. J. 2017, 23, 811-824. [CrossRef]

18. Ferreira, R.T.L.; Amatte, I.C.; Dutra, T.A.; Bürger, D. Experimental characterization and micrography of 3D printed PLA and PLA reinforced with short carbon fibers. Compos. Part B Eng. 2017, 124, 88-100. [CrossRef]

19. Johnson, G.A.; French, J.J. Evaluation of Infill Effect on Mechanical Properties of Consumer 3D Printing Materials. Int. J. Eng. Technol. Innov. 2018, 3, 179-184.

20. Seol, K.S.U.; Zhao, P.; Shin, B.C.; Zhang, S.U. Infill Print Parameters for Mechanical Properties of 3D Printed PLA Parts. J. Korean Soc. Manuf. Process Eng. 2018, 17, 9-16. [CrossRef]

21. Subramaniam, S.R.; Samykano, M.; Selvamani, S.K.; Ngui, W.K.; Kadirgama, K.; Sudhakar, K.; Idris, M.S. Preliminary investigations of polylactic acid (PLA) properties. In AIP Conference Proceedings; API: College Park, MD, USA, 2019.

22. Song, Y.; Li, Y.; Song, W.; Lee, K.; Lee, K.Y.; Tagarielli, V.L. Measurements of the mechanical response of unidirectional 3D-printed PLA. Mater. Des. 2017, 123, 154-164. [CrossRef] 
23. Chamis, C.C. Analysis of the three-point-bend test for materials with unequal tension and compression properties. In NASA Technical Note TN D-7572; National Aeronautics and Space Administration: Washington, DC, USA, 1974.

24. Vgenopoulos, D.; Sweeney, J.; Grant, C.A.; Thompson, G.P.; Spencer, P.E.; Caton-Rose, P.; Coates, P.D. Nanoindentation analysis of oriented polypropylene: Influence of elastic properties in tension and compression. Polymer 2018, 151, 197-207.

25. Huang, T.; Pan, Q.X.; Jin, J.; Zheng, J.L.; Wen, P.H. Continuous constitutive model for bimodulus materials with meshless approach. Appl. Math. Model. 2019, 66, 41-58. [CrossRef]

26. Kuznetsov, V.; Solonin, A.N.; Urzhumtsev, O.D.; Schilling, R.; Tavitov, A.G. Strength of PLA Components Fabricated with Fused Deposition Technology Using a Desktop 3D Printer as a Function of Geometrical Parameters of the Process. Polymers 2018, 10, 313. [CrossRef]

27. Zhang, Q.; Mochalin, V.N.; Neitzel, I.; Hazeli, K.; Niu, J.; Kontsos, A.; Zhou, J.G.; Lelkes, P.I.; Gogotsi, Y. Mechanical properties and biomineralization of multifunctional nanodiamond-PLLA composites for bone tissue engineering. Biomaterials 2012, 33, 5067-5075. [CrossRef]

28. Forster, A.M. Materials Testing Standards for Additive manufacturing of Polymer Materials: State of the Art and Standards Applicability. In Additive Manufacturing Materials; White, L., Ed.; Nova Science Publishers: Hauppauge, NY, USA, 2015.

29. ASTM D638-02a. Standard Test Method for Tensile Properties of Plastics; ASTM: West Conshohocken, PA, USA, 2003.

30. ASTM D695-02a. Standard Test Method for Compressive Properties of Rigid Plastic; ASTM: West Conshohocken, PA, USA, 2002.

31. ASTM D790-02. Flexural Properties of Unreinforced and Reinforced Plastics and Electrical Insulating Materials; ASTM: West Conshohocken, PA, USA, 2002.

32. Bagheri, A.; Buj, I.; Ferrer, M.; Pastor, M.M.; Roure, F. Determination of the Elasticity Modulus of 3D-Printed Octet-Truss Structures for Use in Porous Prosthesis Implants. Materials 2018, 11, 2420. [CrossRef]

33. Brischetto, S.; Ferro, C.G.; Maggiore, P.; Torre, R. Compression Tests of ABS Specimens for UAV Components Produced via the FDM Technique. Technologies 2017, 5, 20. [CrossRef]

34. Dhôte, J.X.; Comer, A.J.; Stanley, W.F.; Young, T.M. Investigation into compressive properties of liquid shim of aerospace bolted joints. Compos. Struct. 2014, 109, 224-230. [CrossRef]

35. Lammens, N.; Kersemans, M.; DeBaere, I.; VanPaepegem, W. On the visco-elasto-plastic response of additively manufactured polyamide-12 (PA-12) through selective laser sintering. Polym. Test 2017, 57, 149-155. [CrossRef]

36. Baich, L.J. Impact of Infill Design on Mechanical Strength and Production Cost in Material Extrusion Based Additive Manufacturing. Ph.D. Thesis, Youngstown State University, Youngstown, OH, USA, 2016.

37. Sayre III, R. A Comparative Finite Element Stress Analysis of Isotropic and Fusion Deposited 3D Printed Polymer. Ph.D. Thesis, Rensselaer Polytechnic Institute, New York, NY, USA, 2014.

38. ANSYS. Academic Research Mechanical, Release 19.1; ANSYS Inc.: Canonsburg, PA, USA, 2019.

39. Bainbridge, J. 3D Printing Filament Properties. Available online: https://github.com/superjamie/lazyweb/ wiki/3D-Printing-Filament-Properties (accessed on 4 June 2019).

40. Mazzanti, V.; Malagutti, L.; Mollica, F. FDM 3D Printing of Polymers Containing Natural Fillers: A Review of their Mechanical Properties. Polymers 2019, 11, 1094. [CrossRef]

(C) 2019 by the authors. Licensee MDPI, Basel, Switzerland. This article is an open access article distributed under the terms and conditions of the Creative Commons Attribution (CC BY) license (http://creativecommons.org/licenses/by/4.0/). 